\title{
Establishing the Benefits of Research Experiences for Undergraduates in the Sciences: First Findings from a Three-Year Study
}

\author{
ELAINE SEYMOUR, ANNE-BARRIE HUNTER, \\ SANDRA L. LAURSEN, TRACEE DEANTONI \\ Ethnography \& Evaluation Research, Center to Advance Research and Teaching in the \\ Social Sciences, University of Colorado, Boulder, CO 80309-0850, USA
}

Received 7 November 2002; revised 25 June 2003; accepted 9 July 2003

DOI 10.1002/sce.10131

Published online 26 April 2004 in Wiley InterScience (www.interscience.wiley.com).

\begin{abstract}
Descriptions of student-identified benefits of undergraduate research experiences are drawn from analysis of 76 first-round student interviews gathered at the end of summer 2000 at four participating liberal arts colleges (Grinnell, Harvey Mudd, Hope, and Wellesley). As part of the interview protocol, students commented on a checklist of possible benefits derived from the literature. They also added gains that were not on this list. Students were overwhelmingly positive: $91 \%$ of all statements referenced gains from their experiences. Few negative, ambivalent, or qualified assessments of their research experiences were offered. The benefits described were of seven different kinds. Expressed as percentages of all reported gains, they were personal/professional gains (28\%); "thinking and working like a scientist" (28\%); gains in various skills (19\%); clarification/confirmation of career plans (including graduate school) (12\%); enhanced career/graduate school preparation $(9 \%)$; shifts in attitudes to learning and working as a researcher $(4 \%)$; and other benefits (1\%). (C) 2004 Wiley Periodicals, Inc. Sci Ed 88:493-534, 2004
\end{abstract}

\section{INTRODUCTION}

Notwithstanding a high level of interest in undergraduate research, and the large number of programs and models, supported both by institutional policies and by funding from private and public agencies, examples of well-designed program evaluations are rare. Research findings upon which sound evaluation strategies might be grounded are even rarer. In this

\footnotetext{
Correspondence to: Elaine Seymour; e-mail: elaine.seymour@colorado.edu

Contract grant sponsor: NSF-AIRE.

Contract grant sponsor: NSF-ROLE.

Contract grant number: \#NSF PR REC-0087611.

Contract grant sponsor: Grinnell, Harvey Mudd, Hope, and Wellesley Colleges.
} 
study, we have sought to offer some answers to a set of questions about the nature and impact of undergraduate research experiences that have been asked of (and by) faculty and institutions that are invested in these programs. This account describes first findings from a 3 -year, qualitative research project, the goals of which are to

clarify, and estimate the relative importance to students of, the benefits of "good" undergraduate research experiences and the processes whereby these are achieved in a sample of science disciplines from the viewpoints of participating and nonparticipating undergraduates and faculty.

This account describes first findings from an analysis of interview data from 76 participating students (largely rising seniors) in eight science disciplines at four liberal arts schools that share a tradition of undergraduate research, and whose approach broadly follows the same summer research apprenticeship model.

\section{CLASSIFICATION AND UTILIZATION OF LITERATURE}

In preparation for this study, we reviewed as completely as possible published articles and evaluation reports that address the benefits of undergraduate research defined as undergraduate engagement in authentic research conducted in intensive summerlong programs under the direct supervision of faculty researchers. In this review, we were concerned to establish what is known with any certainty about the qualities and effects of undergraduate research, thus defined. We also developed the following typology of published work according to its purpose (e.g., research, evaluation), and the completeness and quality of the evidence offered in support of hypothesized benefits to participating students in a variety of models and contexts. For the typology of literature that we offer, and for all discussions of literature, readers are referred to the references given in Table 1.

\section{Type 1: Hypothesized Benefits Are Both Claimed and Well Supported}

Research. Three journal articles and one conference presentation describe the methods and findings of formal research studies that explore the benefits to undergraduates of research experiences $(1,2,3,4)$. Kremmer and Bringle (1) and Kardash (2) both report gains in basic research skills, including oral communication of results. However, Kardash found that gains in formal writing were "very little" enhanced, and higher-order research skills only "somewhat enhanced." Ryder, Leach, and Driver (3) report enhancement of students' understanding of the nature and development of scientific knowledge; and Rauckhorst (4) describes research participants' epistemological development from simplistic to complex ways of "knowing."

Evaluation. Five well-designed evaluations offer complete information on the methods used $(5,6,7,8,9)$. These include three studies that explore the impact of particular program models upon students of color $(5,6,7)$. Three of the evaluations were conducted by researchers at the LEAD Center, University of Wisconsin-Madison $(5,7,8)$.

\section{Type 2: Hypothesized Benefits Are Either Simply Stated, or Claimed But Not Adequately Demonstrated}

Evaluation. Evaluations that provide incomplete descriptions of their methods, and/or design limitations (e.g., 10,11,12,13,14,15,16,17,18). 
TABLE 1

Typology of the Literature in Support of Hypothesized Benefits to Students Participating in Undergraduate Research, According to Purpose and Quality

Type 1: Hypothesized benefits are both claimed and well-supported

Research

(1) Kremmer and Bringle (1990)

(2) Kardash (2000)

(3) Ryder, Leach, and Driver (1999)

(4) Rauckhorst (2001, July)

\section{Evaluation}

(5) Alexander, Foertsch, and Daffinrud (1998, July)

(6) Nagda et al. (1998)

(7) Foertsch, Alexander, and Penberthy (1997, June)

(8) Alexander et al. (1996, June)

(9) Fitzsimmons et al. (1990, March)

Type 2: Hypothesized benefits are either simply stated, or claimed but not adequately demonstrated

\section{Evaluation}

(10) Mabrouk and Peters (2000)

(11) Gates et al. (1998)

(12) McCurdy, Buckner, and Baughman (1998, Dec.)

(13) Humphreys (1997)

(14) Sabatini (1997)

(15) O'Clock and Rooney (1996)

(16) Spencer and Yoder (1995)

(17) Zydney et al. (2002)

(18) Morley, Havick, and May (1998, July)

Descriptive accounts

(19) Chaplin, Manske, and Cruise (1998)

(20) Dunn and Phillips (1998)

(21) Kitto (1998)

(22) Madler (1998)

(23) Costa (1997)

(24) Manduca (1997)

(25) Nikolova Eddins and Williams (1997)

(26) Nikolova Eddins et al. (1997)

(27) Dukes, Kubinec, and Nations (1996)

(28) Voight (1996 Nov.)

(29) Weal and Clarke (1996, Aug.)

(30) Krochalk and Hope (1995)

(31) Byrd et al. (1994)

(32) Holme (1994)

(33) Fletcher (1993)

(34) De La Garza, Anderson, and Lee (1991)

(35) Sanzone (1977)

(36) Shellito et al. (2001)

(37) Orthlieb and Fewster (1994)

(38) Christman (1991)

(39) Dean (1991)

(40) Jones (1991) 
TABLE 1

Typology of the Literature in Support of Hypothesized Benefits to Students Participating in Undergraduate Research, According to Purpose and Quality (Continued)

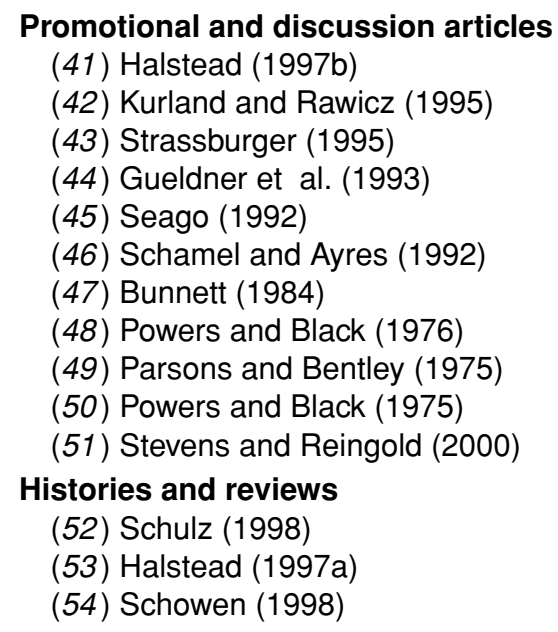

\section{Descriptive Accounts.}

- A large number of articles that describe particular faculty-developed, institutional, or cross-institution programs in which accounts of evaluation methods are missing, incomplete, or problematic (e.g., 19,20,21,22,23,24,25,26,27,28,29,30,31,32,33,34, 35,36). This is the largest body of published work on undergraduate research. Commonly, faculty describe their programs and experiences, offer feedback from participants or alumni, and draw inferences from them.

- Student-authored accounts of their undergraduate research experiences without reference to research or evaluation (e.g., 37,38,39,40).

Promotional and Discussion Articles. Articles in which no evaluation or research evidence is offered (e.g., 41,42,43,44,45,46,47,48,49,50,51). They describe the perceived merits of undergraduate research in general, particular models of activity, and/or the principles and methods by which to install them.

Histories and Reviews. Articles that recount the history of undergraduate research with limited reference to research or evaluation (e.g., 52,53). Reviews that reference evaluation studies, but contain incomplete or problematic accounts of methods used (e.g., 54).

All but three of the 54 sampled articles and reports reference undergraduate research in the sciences (including mathematics and engineering), although we are aware that programs are also offered in the humanities, social sciences, education (28), and in professional education such as nursing (44) and business (15). The tradition seems, however, to be strongest in the sciences.

The preponderance of program descriptions, explication of models, and evaluation efforts rather than research studies is, perhaps, not surprising. As Rogers (1995) originally observed, faculty who develop educational strategies often promote their ideas and experiments, and argue their value and efficacy, largely from direct personal experience. The high degree 
of support for undergraduate programs, despite the small body of evidence demonstrating their benefits, illustrates Rogers' view that, in matters of pedagogical practice, faculty typically draw upon ideas advocated by colleagues that they understand and trust more than upon empirical evidence (see also, Foertsch et al., 1997). It is also understandable that many evaluation components of reports have methodological limitations. Faculty innovators often work alone or in informal groups, with limited funding, access to evaluation expertise, or knowledge of how to monitor their pedagogy in a scholarly fashion. There are, however, ironies in this situation, given their common goal of seeking to build research skills in undergraduates.

Particularly in individual faculty accounts, the problems of small sample size and samples that are self-selected, faculty-recruited, or predisposed by selection criteria to display expected gains are common. Many writers omit, or underreport, the details of their evaluation design and methods of data collection or analysis (particularly where qualitative data are gathered); others offer findings on the basis of samples that are inadequately structured or drawn, or that reflect low response rates. Work that is otherwise thoughtful in seeking to distill the benefits and difficulties of students' research experiences may also be undermined by sampling biases. For example, in the account of Mabrouk and Peters (10), the sample was doubly biased: the authors asked faculty known to them for their own (or their institution's) participation in undergraduate research to identify past and present students who could be contacted as potential sample members. Schowen (54) found that at least $75 \%$ of the 216 Research Experiences for Undergraduate (REU) students who participated in the University of Kansas research programs since 1988 go on to advanced study in the chemical sciences. However, this finding too is compromised because the participants are specifically those who have professed an interest in chemistry, are entering a chemistry program, and are, thus, predisposed to go on to graduate school. Schowen does, however, use a control group ("majors in general, including those who do not participate in research" [p. 76]): most evaluation accounts do not mention comparison or control groups.

Some institutions with a tradition of commitment to undergraduate research have sought to demonstrate the value of their programs by reference to institutional data. Most commonly, institutions seek to demonstrate the numbers of former undergraduate researchers choosing graduate school or high-level professional careers $(5,7,8,9,10,11,13,14,15,24,28,32,33,34$, $37,39,40,42,43,50,52,54)$. The difficulties with this approach are insufficient evidence for a causal link between undergraduate research experiences and particular career choices; sample biases (again) created by faculty recruitment or self-selection of high-achieving students who are predisposed to careers requiring higher education; lack of data on the nature of student researchers' experiences over time, or on their processes of career-choice development. ${ }^{1}$

These data-gathering problems leave a "black box" between program goals and activities on the one hand, and the outcomes claimed for them on the other. They also point to the need for research that grounds the tacit and articulated hypotheses of faculty practitioners (and their institutions) and investigates the nature and strength of linkages between student experiences and the benefits claimed for them. Both the National Science Foundation and the Council of Undergraduate Research have called for studies that offer a critical analysis of undergraduate research and that may validate its place in the science curriculum (e.g., 47,48).

\footnotetext{
${ }^{1}$ A fuller, classified review of evaluation studies and accounts that address the alleged contribution of undergraduate research to career choice or clarification is presented immediately before our findings on this issue in the section discussing the "career clarification" category.
} 
Despite their limitations, Type 2 accounts are important as a collective record of faculty and student expectations, observations, and personal experiences of the benefits of undergraduate research. Although most claims cannot, as yet, be validated, they are nevertheless of great value in the development of protocols for interview-based inquiry, and for reference in the development of instruments designed to test the strength of particular claims. Hypothesized benefits are of different orders: some are very broad, some are very specific. We have grouped below the most commonly mentioned benefits to students. However, project descriptions often cite as undergraduate research beneficiaries faculty researchers, their institutions (especially in schools without a graduate program), industry, science as an enterprise, and science literacy as a national resource. The following citation list gives some indication of the relative frequency with which particular benefits for students per se are described across the literature:

- Increased student interest in the discipline $(5,7,8,9,13,21,24,25,26,28,29,30,32,33,37$, $44,45,46,47,49,50,53)$; increased recruitment of students of color into the sciences $(5,7,13,18,20)$; increased persistence $(5,6,19,25,43)$;

- Enhanced career preparation: greater readiness for more demanding research and for professional careers in the sciences $(5,7,8,9,13,15,20,24,25,33,38,40,43$, $45,50,52)$; professional socialization $(20,26,44)$; and opportunities for networking $(10,15)$;

- Clarification, confirmation, interest in, or choice of, a career path (including graduate school) $(1,5,7,8,9,10,11,13,14,15,17,24,28,32,33,34,39,40,42,43,50,52$, $53,54)$;

- Increased skills: research and lab techniques $(1,2,5,7,8,9,10,11,14,17,19,20,42)$, working collaboratively $(10,11,14,20,21,25,26,46)$; communication (writing, presentation, and argument) $(2,10,11,17,19,20,25,26,28,29,42,43,46)$; and leadership $(10,11,14)$;

- Gains in: critical thinking and understanding how to approach research problems $(10,14,17,19,25,26,37,38,39,40,43,46,52)$; knowledge $(2,14,47)$; and science literacy $(7,8,24,25,33,44,50,52,54)$;

- Increased understanding of: the research process $(5,7,8,9,11,14,20,30,34,43)$; how scientists think $(5,7,8,9,19)$; how scientists work on real problems $(11,12,14,15,19,20$, $25,28,29,30,32,33,34,41,43,44,50,53)$; how scientific knowledge is built $(3,4)$;

- Increased self-confidence in ability to do research $(5,7,8,10,14,19,23,37,39,43,44)$ and self-esteem $(15,44)$;

- Improved approach to learning: shift from passive to active learning $(19,23,26,45,46$, $52,53,54)$;

- Becoming part of a learning community $(5,6,7,12,15,19,21,33,41,53)$ (especially for students of color) $(5,6,7,19)$; bonding with faculty (and, thereby, the discipline/career path) $(6,7,8,11,12,15,25,26,33,44,50,53)$.

Many hypothesized benefits target majors, potential majors, or potential graduate students. More rarely, authors (e.g., Bunnett [47]) argue that all students who participate will benefit, and not only those who plan a research career.

What is surprising is that references to students' increased understanding of the nature of scientific knowledge, and how it is created, refined, and challenged, are found in relatively few accounts. Descriptions of the development of "critical thinking" and thinking about research problems "like scientists" are often vague. We also found no descriptions of how faculty use their contact time with their student researchers to deepen the "understanding" 
or "thinking" that they hope to see as an outcome of undergraduate research experiences. ${ }^{2}$ Indeed accounts of the processes by which benefits to students may accrue are generally missing. ${ }^{3}$

Two notable exceptions are papers by Ryder, Leach, and Driver (3) and Rauckhorst (4). Ryder et al. explored changes over 5-8 months of research work in students' understanding of how the validity of knowledge claims is evaluated, and of the role of theory in shaping research questions. The limitations of this otherwise useful, in-depth ethnography are its small sample $(N=11)$ and the difficulties of comparability arising from its contextsenior projects in science degree courses at a British university. Rauckhorst's presentation described student transitions in their ways of knowing using Baxter-Magolda's epistemological reflection model of four categories of intellectual development from simplistic to complex thinking. The most commonly found change in students' ways of knowing, noted in $40 \%$ of the undergraduate research participants, was from Category Two, "transitional knowing" (where students believe that some knowledge is less than absolute and focus on finding ways to search for truth) to Category Three, "independent knowing" (where students believe that most knowledge is less than absolute and individuals can think for themselves).

Although improvement of students' research skills is a commonly referenced goal or benefit, accounts rarely group skills by their level of difficulty or by other qualities. Kardash's study (2) of two samples of summer and academic-year research participants is an exception. Those skills that students felt were enhanced (but that Kardash defines as of "lowerorder") included communicating their research results orally (but not, however, in formal writing), observing and collecting data, relating their results to the "bigger picture," and understanding contemporary concepts in their fields. However, she found only modest gains in certain "higher-order skills involved in doing science; namely, identifying a specific question for investigation, translating the question into a working hypothesis, designing a theoretical test of a hypothesis, and reformulating the hypothesis on the basis of one's experimental results." Kardash concludes that, although undergraduate research experiences (UREs) "are clearly successful in enhancing a number of basic scientific skills, the evidence is less compelling that UREs are particularly successful in promoting the acquisition of higher-order inquiry skills that underlie the foundation of critical, scientific thinking" (p. 196).

Alongside questions about what students gain from undergraduate research experiences, and how these gains are made, lie the parallel issues of what is "lost" (if anything) by students who do not participate, and with what consequences-including their career choices and performance. $^{4}$ As most studies lack comparison or control groups, this has been little discussed.

Finally, a limited number of studies discuss students' reasons for wanting to participate in undergraduate research $(8,12)$. Most hypothesized motives focus on careers rather than education; that is, resume enhancement, preparation for graduate or professional careers (12), and clarification of career interests (8). However, as faculty accounts of their goals for students lie in the opposite direction and stress students' educational and professional growth, it is important to learn what motivates students to participate-or not to do so.

\footnotetext{
${ }^{2}$ In the only Type 1 evaluation study that has investigated learning gains as a result of undergraduate research experience, Fitzsimmons et al. (9) found that "substantive knowledge of the field" was not gained.

${ }^{3}$ Exceptions are Type 1 evaluations of programs targeting students of color that describe the role of mentors in increasing retention among these students.

${ }^{4}$ Mabrouk and Peters (10) are among the few authors who discuss this.
} 


\section{RESEARCH QUESTIONS}

This pilot study was conceived by the researchers ${ }^{5}$ as the first step in addressing some fundamental questions about the benefits (and costs) of undergraduate engagement in facultymentored, authentic research undertaken outside of class work, about which the existing literature offers few findings and many untested hypotheses. Our overarching goal is to clarify the nature and value of this common type of undergraduate research experience in the shorter and longer term, as perceived by both students and faculty who do, and do not, participate.

This investigation entails questions that begin with "how" as well as "what." We need to know what benefits accrue as direct and indirect consequences of undergraduate research experiences, and their relative importance to students by the conclusion of the experience, later in their education, and beyond graduation. To gain insights into the principles on which "good" research experiences are based, we also ask, "By what processes (i.e., "how") are such benefits achieved?" This involves inquiry into the nature of working relationships with faculty and peers that characterize students' research experiences, and the significance of other processes that shape outcomes for students-whether planned by faculty, structured by departments, or arising from the nature of effective research experiences. We also seek to identify variations in undergraduate research participation, experiences, and outcomes for women and men, and (in so far as sample adequacy permits) for white students and students of color.

\section{RESEARCH METHODS}

\section{Choice of Program Model and Research Sites}

Our literature survey revealed four common models of summer-intensive undergraduate research, although, in practice, many programs include elements from one or more models. The goal for each model defines the timing and character of students' experiences.

- The goal of retention programs is persistence to graduation for undergraduates in (largely) science disciplines, and/or for women and students of color who are underrepresented in those majors $(5,6,13,19,24,26,43)$. As most field-switching occurs before the start of junior year, these programs target freshmen and sophomores;

- In career promotion programs the overall goal is recruitment-more rarely of high school students into college; more commonly, of undergraduates into graduate school and science-based careers; increasingly, recruitment of underrepresented groups. Programs for nonminority undergraduates often start the summer after junior year; those targeting students of color often begin the summer before college entry. Program descriptions stress developing or confirming student interest in the discipline $(14,24,50,52)$ and/or professional orientation and preparation $(10,12,14,24,50,52)$;

- Research "apprenticeships" (including both summer and all-year participation) are offered largely (though not exclusively) to juniors or seniors. Participating faculty mentor single students or small groups $(3,5,6,7,8,9,13,19,20,21,24,26,27,28,32,33$, $34,35,44,45,46,47,53)$;

\footnotetext{
${ }^{5}$ The research team is part of Ethnography \& Evaluation Research (E\&ER) at the Center to Advance Research and Teaching in the Social Sciences (CARTSS), the University of Colorado at Boulder. E\&ER specializes in research and evaluation projects where ethnography is an appropriate method, given the nature of the research questions. Since 1989, the research focus of the group has been issues in science education at the college level.
} 
- "Research-based learning" (25) involves pedagogical changes that incorporate research-like experiences into the classroom throughout, or at any time during, undergraduate education $(8,20,23,25,26,27,28,32,46,49,54)$.

The latter two types of program share some common goals: increasing interest in science $(5,8,9,13,21,24,25,26,29,30,32,46,49,50)$, for all students $(47)$; understanding the nature of science and of scientific knowledge, processes, and methods $(32,34,41,44,45,46,47,48,50)$; development of scientific reasoning, and active, direct learning of what scientists do $(10,11$, $12,14,15,19,20,29,30,32,33,34,35,41,43,44,45,46,50,52,53)$.

In the interests of a coherent research design with limited variance, we chose to focus on summer research apprenticeships for entering seniors, partly because the summer apprenticeship model of undergraduate research is the most common type. Although it combines elements of both career promotion and education enhancement, it is, nevertheless, more homogeneous than other hybrid models.

Although many types of institutions offer summer research apprenticeships, liberal arts colleges have a long-standing collective experience with this type of program. Undergraduate research experiences are also seen as contributing to the strong record of these schools in sending a disproportionately high fraction of their science graduates to graduate school. We propose that it is feasible to assess whether and how this common, well-established model of undergraduate research produces the array of beneficial outcomes claimed for it. For this research study, therefore, we selected four liberal arts colleges that share a history of apprentice-style undergraduate research, and that offer institutional support in securing the participation of students and faculty. They are Grinnell College, Harvey Mudd College, Hope College, and Wellesley College (which is a women's college).

All four institutions offer 10-week summer research programs in three "core" sciencesphysics, chemistry, and biology — with two to four additional programs in other sciences: computer science, engineering, biochemistry, mathematics, and psychology. Students usually undertake their first summer apprenticeships as rising juniors, although some begin earlier. These schools also offer places to students from other (often smaller) liberal arts colleges (e.g., as part of REU programs). The selection and student-project matching processes vary somewhat by department and institution in degree of formality. Students work either individually or in small groups with faculty researchers on ongoing, externally funded projects. They commonly develop particular pieces of their advisors' research and "make them their own" (particularly if they spend more than one summer on a project). However, they do not propose topics independent of existing faculty projects. All schools stress the preparation and presentation of the students' work in formal, endof-summer presentations and offer financial support to enable students to present at disciplinary meetings with their faculty advisors. Program goals across all four schools include increasing interest in science; enhancing students' understanding of the nature of science, scientific knowledge, and the processes and methods involved in its construction; development of scientific reasoning; and active, direct learning of what scientists do. Senior members of each school facilitated the research (e.g., in generating sample lists), but the researchers were entirely unconstrained in their access to potential interviewees or in any other way. The main research disadvantage of these four institutions was their small number of students of color (notwithstanding their ongoing efforts to increase this representation). However, students of color were recruited for the samples wherever possible. $^{6}$

\footnotetext{
${ }^{6}$ Because of the small number of students of color in our sample, the race or ethnicity of those students whom we quote is not indicated so as to protect their anonymity.
} 


\section{The Research Design}

This qualitative inquiry was designed to explore issues in depth and over time, and to provide the information upon which well-grounded measurement instruments could subsequently be developed for program evaluation. Data gathering is continuous over the 3 years of the study, of which 2 years have been completed. It explores student-defined benefits, and the process by which these are acquired, through in-depth interviews at three points in time with a cohort of 76 (largely) rising seniors who were engaged in research in Summer 2000, on each of four campuses. At the three colleges with students of both sexes, the distribution of this cohort was $69 \%$ male and $31 \%$ female.

Where several students worked with a single faculty advisor $(N=20)$, they were interviewed in focus groups. Other students were interviewed singly $(N=56)$. Interviews took between 60 and $90 \mathrm{~min}$. Cohort members were interviewed for a second time shortly before the graduation of the seniors in Spring 2001. They were interviewed (by telephone) for a third time, as graduates, beginning in Summer 2003.

The faculty advisors for this group of students $(N=55)$ were also interviewed in Summer 2000 , along with nine administrators with long experience of undergraduate research programs at their colleges. In addition to documenting the nature, and relative importance, of student benefits and how these are achieved, we are currently exploring the degree of convergence and divergence on these issues between participating undergraduates on the one hand, and their faculty advisors and program administrators on the other.

The student interview protocol focused upon the nature, value, and career consequences of undergraduate research experiences, and the methods by which these were achieved, as perceived by all interviewees. ${ }^{7}$ It explored how students learned about the program, and were selected and matched with particular faculty advisors and projects; their gains in learning, skills, and in understanding how science "is done"; gains that they defined as immediate, longer term, or transferable; their experiences of faculty as mentors, and with both peer researchers and faculty as colleagues; connections between the experience and their career aspirations; issues of gender and race/ethnicity (as appropriate); and, overall, which aspects of the experience they considered of most value and why. In addition, late in the interview, an array of possible benefits derived from the literature was used as the basis for a "gains" checklist that included all categories of faculty-defined gains. We made no presumptions, either about the completeness of the list or about the relative importance of items. It was presented to students as "what faculty think students may gain from undergraduate research." They were asked whether they had gained any of the benefits on the list (and to what degree); whether they had gained any of these by other means; and what gains they had made that were not included in the list. In all cases, we asked students to expand on their answers and to describe how they saw the benefits that they had received as having arisen.

In a second set of interviews just prior to graduation, we asked the same student group to reflect on all of their research experiences as undergraduates, to comment on the relative importance of their research-derived gains, and also on their significance, both for the careers they planned, and for other aspects of their lives. In the third (final) set of interviews approximately 20 months from graduation, they are asked to offer a retrospective summary on the origins of their career plans, the role that undergraduate research played in them, and what other factors influenced their decisions and to comment on the longer term effects of their research experiences as undergraduates, most especially the consequences for their career choices, as well as their current educational or professional engagement.

\footnotetext{
${ }^{7}$ An electronic copy of this protocol is available on request to the authors via elaine.seymour@ colorado.edu.
} 
Our student comparison group $(N=63)$ for the study is composed of four groups: (1) students who applied for, but who were unable to secure a research position on their campus by their presenior summer, (2) students who chose not to apply for a research position, (3) students who applied only at a late stage in their undergraduate careers (given the requirement of a senior thesis), (4) students who chose alternative experiences. The latter included internships, and clinical, field, or research experiences in other institutions or contexts (such as research or commercial labs). These data allow exploration of alternative ways in which students may make the kinds of gains that faculty have sometimes assumed are exclusive to undergraduate research. Postgraduate telephone interviews with the comparison group were conducted alongside third-round interviews with the original cohort. The total number of students sampled is, thus, 139.

Finally, we interviewed a small sample $(N=14)$ of faculty in the same set of disciplines on each campus who (either in the summer or in the academic year) (1) never, rarely, or only occasionally undertake research with undergraduates, (2) no longer do so, or (3) are currently taking time out from research with undergraduates. From these data sources, as well as from the main sample of faculty advisors, we are exploring the conditions under which faculty engagement in undergraduate research occurs and the nature of its costs and benefits to faculty.

In this report, we are concerned with a single subset of the student observation data set; that is, student-identified benefits gained from undergraduate research, as ascertained from analysis of the first-round student interviews gathered at the end of Summer 2000.

\section{Methods of Data Transcription, Coding, and Analysis}

All interviews (single and group) were tape-recorded and transcribed, with the prior permission of the interviewees. In the case of students, this permission was in writing. Tape recordings of interviews and focus groups were transcribed verbatim into a word-processing program and submitted to The Ethnograph (Seidel, 1998), a set of computer programs that allows for the multiple, overlapping, and nested coding of a large volume of transcribed documents to a high degree of complexity. Each line-numbered transcript was searched for information bearing upon the research questions. Information was commonly embedded in speakers' accounts of their experience rather than offered in abstract statements. This allowed transcripts to be checked for internal consistency between the opinions or explanations offered by informants, their descriptions of events, and the reflections and feelings these evoke.

Lines or segments referencing issues of different type, or perceived importance, were tagged by code names. There were no preconceived codes: each new code name references a discrete idea not previously raised. However, given the focus on student accounts of their gains, all files were carefully checked for gains-related statements using the interview protocol as a guide. Because answers to the same question were often not of the same character, or do not cover the same set of issues, codes were never developed on the basis of the questions asked, but always by the nature of the responses given. Interviewees often made several points in the same sentence or speech segment: each was separately coded. Information is given both in answers to questions, and in more spontaneously offered comments, narratives, and illustrations. As hand-coding of the interview transcripts was completed, each code was entered into The Ethnograph, creating a data set of all student observations. Groups of codes that clustered around particular themes were given domain names, and a branching and interconnected structure of codes and domains was gradually built into a code book which, at any point in time, represented the state of the analysis. 
Frequencies were run for codes across the data set, and for important subsets (e.g., in the student samples, by discipline, institution, gender, or ethnicity). The frequency counts allowed us to construct tables that describe the relative weighting of particular issues. As they are not (by design) drawn from random samples, these numeric representations were not subjected to tests for statistical significance. However, they hypothesize the strength of particular variables and their relationships that may, subsequently, be tested.

The ethnographic analyst is always concerned not to overestimate the weight of opinion on any point. Also, it is not always possible to discern identities of particular interviewees when transcribing focus group interviews. Therefore, certain conservative counting conventions were followed: only the first statement on any issue by the original speaker was counted. In focus groups, where several other speakers agreed with a point already counted, only the first of these statements of agreement was added to the count. This yielded a maximum of two counts per focus group and one count for single interviews. Thus, the total count of expressed opinion in support of any point made is likely to be an undercount of the expressed strength of opinion on that point. Most numbers presented in this account are based on counts of discrete observations that reflect these counting conventions. However, for some issues of special interest, where this is possible, we offer the number of students who made a particular observation.

\section{FIRST FINDINGS ON THE BENEFITS OF UNDERGRADUATE RESEARCH}

Students in the first set of interviews were overwhelmingly positive about their undergraduate research experiences: $91 \%$ of all statements about benefits referenced gains-some that were included in the protocol checklist, along with many that were not. "Negative" statements (only $4 \%$ of student responses) were not criticisms of the experience, but indications that a particular gain had not been made. Another $4 \%$ provided qualified, ambivalent, or "mixed" assessments about the extent of any gain. The benefits described were of seven different kinds (Table 2).

While benefits in each of these categories have been described in the relevant literature, no account has, as yet, offered evidence that comprehensively illuminates their nature and meaning for students, nor that clarifies their relative importance. ${ }^{8}$ From this student data set, we were able to examine in some detail the quality of the benefits that the undergraduate research participants described and to rank them according to how often they were cited. In what follows, we describe and discuss the particular types of gain that comprise each of the six largest categories. ${ }^{9}$ In most instances, we refer to the percentage of all reported gains (i.e., students' positive observations) in any particular category.

Two categories of benefits, almost equal in size, account for half $(56 \%)$ of all the gains reported by students in this sample. We labeled them, "thinking and working like a scientist" $(28 \%)$ and "personal/professional gains" (28\%). However, the largest single group of reported gains falls within the personal/professional gains category: increased confidence to "work as a scientist" accounted for three quarters (74\%) of that category (Table 3 ) and

\footnotetext{
${ }^{8}$ Findings from Type 1 research and evaluations highlight particular benefits of undergraduate research. There are a number of benefits reported by our student sample that are not mentioned in this literature, and the converse-some benefits are claimed in the literature that the students in our sample did not report. There are a number of Type 2 accounts, and some evaluation reports (e.g., 5,6,7), of undergraduate research programs whose primary goals are to increase recruitment and retention among students of color. These issues are not addressed in this study.

${ }^{9}$ The very small group of "other" observations shown in Table 2 is not included in this discussion.
} 


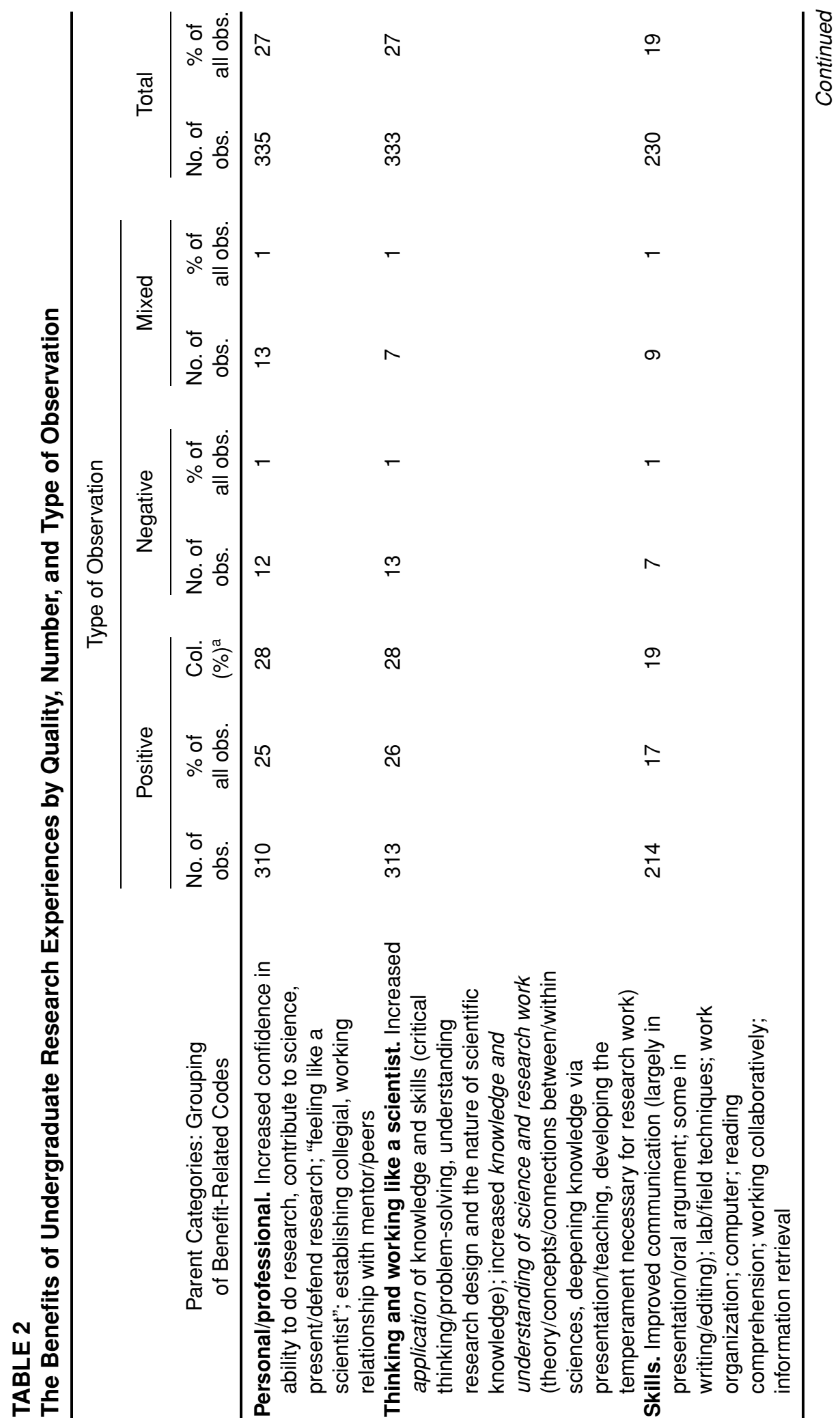




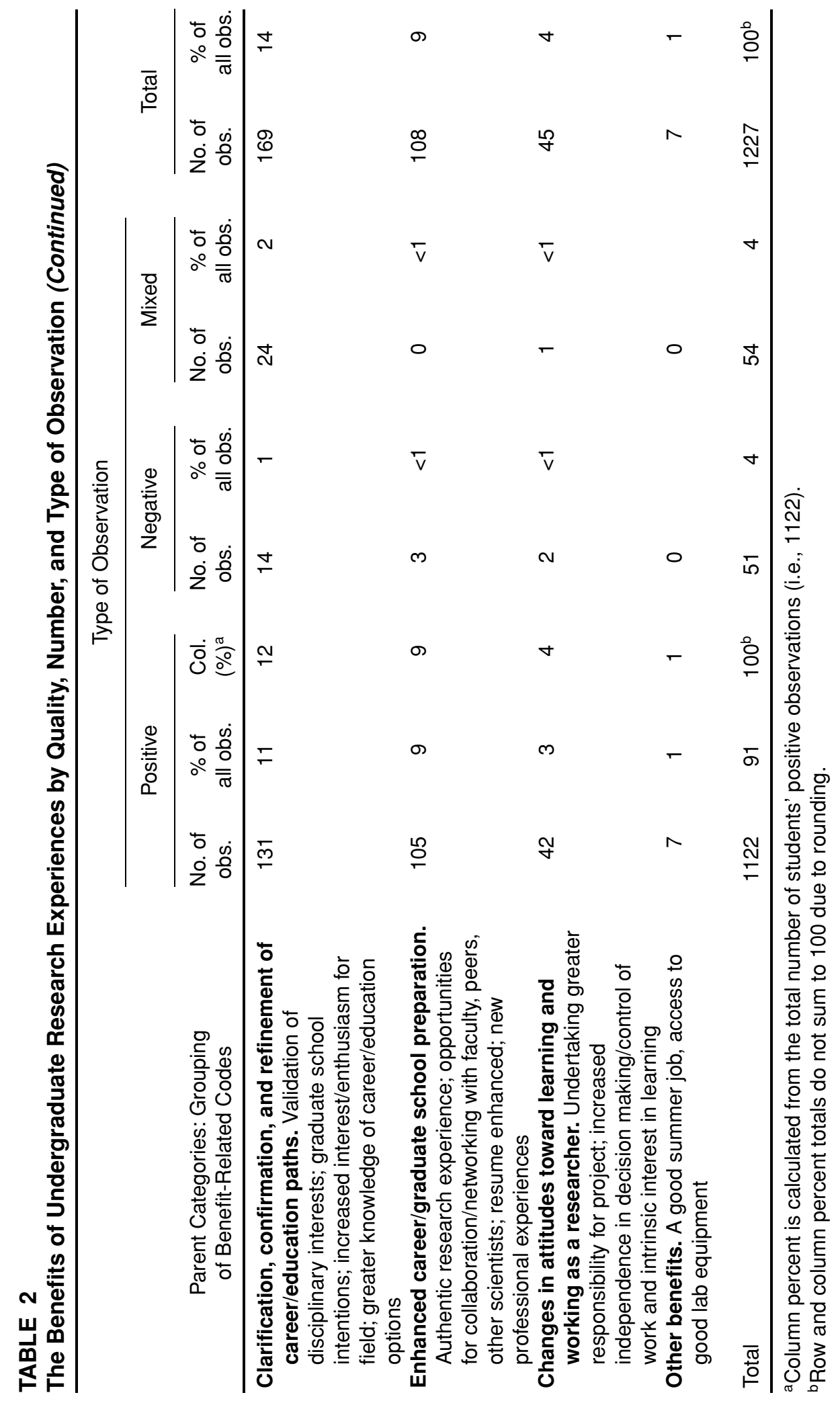


TABLE 3

Students' Positive Observations on Personal/Professional Gains from Their Undergraduate Research (UR) Experience

\begin{tabular}{lrr}
\hline \multicolumn{1}{c}{ Quality of Observation } & $N$ & $\%$ \\
\hline Increased confidence & 90 & 29 \\
In ability to do research & 33 & 11 \\
In contributing real knowledge to science & 123 & 40 \\
Subtotal & & \\
Increased confidence in "feeling like a scientist" & 30 & 10 \\
Because of being taken seriously by others & 28 & 9 \\
In general (i.e., nonspecific statements) & 11 & 4 \\
Because of ability to do research & 6 & 2 \\
Because of ability to contribute to science & 4 & 1 \\
Because of increased understanding of the nature of science & 3 & $<1$ \\
Because of presenting research & 2 & $<1$ \\
Because of possibility of scholarly publication & 1 & $<1$ \\
Because of gain in writing skills & 85 & 27 \\
Subtotal & & \\
Increased confidence (not related to "feeling like a scientist") & 11 & 4 \\
In presenting/defending research & 4 & 1 \\
In general (i.e., nonspecific statements) & 4 & 1 \\
In being taken seriously by mentor and others & 3 & 1 \\
In understanding of the nature of science & 22 & 7 \\
Subtotal & 230 & 74 \\
Subtotal for all increased confidence & 51 & 16 \\
Establishing a mentoring relationship with faculty & 29 & 9 \\
Peer/professional collegiality (i.e., with other UR students) & 80 & 25 \\
Subtotal for all mentoring and peer collegiality & 310 & $100^{\text {a }}$ \\
Total & & \\
\hline
\end{tabular}

apercent total does not sum to 100 due to rounding.

(by calculation) was $21 \%$ of all 1122 positive observations. For this reason, we present an explanation of the contents of the personal/professional gains category first in the following descriptions of content for each category of student benefits.

\section{PERSONAL/PROFESSIONAL GAINS}

Students described a set of benefits that link personal gains to their perceived professional value. As indicated above, this was one of the two dominant categories of gains. It accounted for $27 \%$ of all students' observations and $28 \%$ of all students' positive observations (Table 2). Within this large category, nearly three quarters (74\%) of students' comments referenced increases in confidence, making it (as indicated above) the largest single set of gains. This was not a general, or purely personal, gain in confidence, but was specifically related to engaging in science and scientific research. The other two components of the personal/professional gains category were the benefits of establishing a collegial, working relationship with faculty mentors (16\%) and with peers $(9 \%)$ (Table 3). 


\section{Increased Confidence}

When students talked about gaining greater confidence, it was entirely in the context of their engagement in research as emergent scientists. Twenty-nine percent of comments describing personal/professional gains referenced increased confidence in the ability "to do" science research, and $11 \%$ mentioned increased confidence in the ability "to contribute" to science. Taken together, feeling confident to work creatively and independently as a researcher and to make meaningful contributions to science was the most often-described group of benefits. ${ }^{10}$ Students spoke of feeling confident enough to take decisions about next steps in their projects that were increasingly independent of their faculty advisors. Typical of these observations is the following:

At the beginning, I asked a lot of questions to get a good basis and a good idea when I didn't really know what I was doing. But by the end of the summer, I didn't speak to my advisor so much, because I would just do it. (Female biology major)

They spoke of increased confidence in their ability to work out how to address technical problems, and an enhanced readiness to tackle new lab instruments:

I now feel confident that I can walk into any room with any instrument and figure out how to make that instrument work.... When I look at somebody's list of 10, 15 different methods of analysis they're using, I can look down that list and say, "I know how to do half of these, and another half of them I can figure out pretty easily," based on things I've done. (Male biochemistry major)

Bonding with a professional identity (often expressed as "feeling like a scientist") accounted for another $27 \%$ of students' reports of personal/professional gains. Most students who cited this as a benefit also explained how confidence grew along with a newfound sense of professional belonging:

The summer's research was sort of the first step in becoming a true biologist. The nature of the research is such that there are long periods of waiting before we can obtain data. And so some days were particularly trying, but as a whole, I look back on it fondly. I feel like I'm really learning what it's like to be a scientist. (Male biochemistry major)

Part of gaining confidence as a working scientist was the experience of addressing (and perhaps surmounting) methodological challenges and/or technical setbacks:

When I really realized some of the frustrations you can have with research, I think I learned that that's a part of being a scientist, is dealing with that. (Male chemistry major)

Ten percent of observations in this category linked increased confidence to their experience of "being taken seriously by others":

It's that first time where they say, "Well, I want you to try this out. We've never done this before. We don't know how it's going to come out." And you do it, and it works, and everyone is all excited about it... The staining that I've been working on, we sent it off to the person who made the toxin to show them... and he sent an e-mail back saying it was the most beautiful thing ever! He wanted to put it in his catalog. His catalog! He wanted

\footnotetext{
${ }^{10}$ Increases in students' confidence grounded in their ability to do research (sometimes described as "professional self-confidence"), or more broadly gains in "self-esteem," were found in three Type 1 studies $(5,6,7)$ and claimed as a benefit in seven Type 2 studies $(10,14,19,23,37,39,43)$.
} 
our pictures! So it was like, "Wow! I did something that someone else who is... that I've always held in esteem...." You know, you never really think you'll ever quite be up to that level, and he thinks that I did something that's really important! (Female biology major)

Presenting an account of the summer's work to other students and faculty and offering a poster at a conference were cited as contexts in which the serious interest of othersespecially that of professional scientists-prompted a dramatic rise in professional confidence and identity:

When I was at the conferences, especially the one last year, I felt truly that I was a scientist. I was amidst scientists. I was just, you know, completely surrounded by them, and they were... I was talking to them about my research and they were talking to me. And they, I could see them talking to me... not as if I was lower to them, but as equal to them. And that made me feel really good.... Some people even asked me if it was my doctoral work. (Male physics major)

Critical elements in this experience were planning the presentation, learning how best to explain the work to others, answering questions from the floor and discussing points raised in public. Faculty built up students' proficiency and confidence by practicing these skills in weekly research group meetings.

Contributing to a scholarly article for publication with their faculty advisor was a relatively rare experience for these rising seniors $(N=5)$, although we predict that a larger number will be so engaged in later interview rounds. However, for those who were learning the process of writing, editing, and collegial review, these as well as the possibility of publishing a scholarly article were a major source of confidence:

We had this really great paper, and we had it all on poster board. He just tore it apart. We had to unglue it from the poster board and just basically rewrite the whole thing. So I had this feeling that I was this big great writing person, and he just totally took that apart. And it was when I rewrote that paper, and I was reading it again and saying, "Okay. . . this actually does seem realistic." And it wasn't the egotistical blown-up ideas that I had before. It was actually sounding like something real... . I really enjoyed presenting it because I had confidence in the paper. (Male biology major)

All the observations of these students on the dimensions and causes of increased confidence $(N=230)$ are detailed in Table 3. The two types of reported benefits that account for the balance $(25 \%)$ of the personal/professional gains category are discussed below.

\section{Establishing a Collegial Working Relationship with Faculty Mentors}

Students greatly valued the opportunity to work one-on-one with faculty and cited development of a collegial working relationship with their mentors as a distinct benefit of doing undergraduate research. This gain contributed $16 \%$ to all gains in the personal/professional category. ${ }^{11}$ Students had more to say about their mentors in a large body of observations that explain how the benefits described here were enabled by their faculty advisors. As such, they will form part of a separate, subsequent analysis of the processes that typify effective undergraduate research experiences.

${ }^{11}$ Developing collegial relationships with faculty mentors was found to be a benefit in four Type 1 studies $(5,6,7,8)$, and was claimed as a benefit in eight Type 2 accounts $(11,12,15,25,26,33,36,51)$. 
Undergraduate research often provided students with their first experience of working alongside faculty as partners. Students emphasized the qualitative difference in their interactions with faculty while pupils in the classroom and when working alongside faculty in a shared project:

I've gotten to know all the faculty.... I actually see them more as peers. As a researcher, they are your peers; you're working with them. And you ask them questions, and they are just as excited to know what I'm doing as I am to know how they're doing, or what they could help me with.... It gives a totally different aspect than being a student. . . and you don't have to be intimidated by them anymore. (Male biology major)

While treating students as professional colleagues is normal practice for faculty working with undergraduate researchers, the shift from a hierarchical and respectfully distanced relationship to one based on partnership in a common enterprise had a powerful impact on students. This too served to bolster their confidence:

When I go in and explain what I found to him and he responds with my first response to the question, and I can say, “Now, I thought of it a little bit more, and I don't think that's exactly it," it's really wonderful to be in such a give-and-take with a professor, where the professor doesn't know all of my ideas before I come to it.... It's really neat to be with a professor and be working through something that is new for both of us. (Female mathematics major)

Students expressed surprise that faculty asked for their opinions and respected their input:

\begin{abstract}
He said he's learning as much from us as we are learning from him... . During our semester meetings, he'll start taking out his notebook and start writing down things we are saying.... It makes you feel proud when something you said is important enough for someone like him, who has been researching this stuff much longer than we have-especially when it seems like a moment of insight, like something he hadn't thought of before. . . It just feels great when somebody takes me seriously, or takes my work seriously. (Male psychology major)
\end{abstract}

They felt trusted to carry out important research tasks, and, as their knowledge and experience grew, were supported in taking independent decisions. Advisors modeled for them the normal processes of science, including consulting with colleagues, dealing with setbacks, and making complex decisions. This was a valuable professional learning experience in its own right, and made an important contribution to other benefits.

\title{
Development of Professional Collegiality with Peers
}

Students also cited as $9 \%$ of personal/professional gains the benefits of developing collegial working relationships with members of their research groups. This was, to most students, a new experience that (as with their relationships with faculty) involved reappraisal of their accustomed ways of relating to classmates. It included the pleasurable sense of "belonging to a community" of like-minded individuals who are working toward similar goals, and discovering their intellectual strengths. ${ }^{12}$ This included learning to take each other's ideas and work seriously:

\footnotetext{
12 The benefits of peer collegiality are discussed in two Type 1 evaluations $(5,8)$. "Belonging to a community of learners" (which encompasses collegiality with coworkers) was reported as a benefit in three Type 1 studies $(5,6,7)$ and claimed or described as benefits in several Type 2 accounts $(12,15,19,21,33)$.
} 


\begin{abstract}
We would also have meetings for lunch once a week where everybody from the two labs would get together and we'd discuss what we're working on... Even though I'm not specifically working on that project, what their work is influences my project and vice versa. So we would... discuss what had been going on-new results, something good or bad that had happened.... Plus, that provides time for insight. . . maybe they're thinking about this problem a different way than you. (Female chemistry major)
\end{abstract}

The development of collegiality among research peers opened up interesting discussions, and underscored the value of discussion as a professional habit. It offered students new and multiple perspectives on their work, and on its problems, and yielded help when needed:

\begin{abstract}
With my (research partner), we were pretty much working on it together. Especially going in as freshmen and not having any research experience. I think if we were alone, we just couldn't have mustered the strength to go on with it because it's so open-ended and so overwhelming - to not have someone else to talk to would have made it very difficult. (Male physics major)
\end{abstract}

As indicated above, developing collegial working relationships with both faculty and fellow researchers also contributes to an iterative, spiral process that increases confidence and enables and reinforces other gains. The experience of working collegially with mentors and research peers offered insights into "what it would be like" to work professionally in the field, and reinforced the sense that this was "a real-world work experience."

\title{
“THINKING AND WORKING LIKE A SCIENTIST"
}

Almost equal in size to the personal/professional category was a set of benefits that, collectively, may be described as "thinking and working like a scientist." This category accounted for $27 \%$ of all students' observations and was $28 \%$ of all students' positive observations of their experiences (Table 2). As indicated in Table 4, reports of benefits were, broadly, of two kinds: gains in knowledge and/or understanding of science and research (43\%); and increases in the ability to apply knowledge and skills (57\%).

\section{Gains in the Application of Knowledge and Skills}

This set of gains may be thought of as a process that is encouraged by active engagement in research. Many students discover they can apply their knowledge and skills to real problems; some begin to see how to choose and frame problems so that they can be approached scientifically; and a few grasp the implications of these choices for the nature and certainty of the answers thus generated. Our data suggest that the experience of doing research holds the potential to encourage students to take a sequence of steps from application to design and hence to generalization or abstraction; that is, from more concrete to more abstract stages of thinking. Indeed, students often represented this group of gains as an epiphany. In many observations (43\%) students had been enabled to bring their critical thinking, problem-solving skills, and knowledge to bear on real research problems; some $(8 \%)$ had gained insights into how to generate and refine research questions and to develop alternative designs to address them; and a small number (3\%) brought to their projects a clearer understanding of the nature of scientific knowledge and its construction. One or 
TABLE 4

Students' Positive Observations on Gains Made in "Thinking and Working Like a Scientist"

Quality of Observation

N $\%$

\begin{tabular}{|c|c|c|}
\hline \multicolumn{3}{|l|}{ Gains in the application of knowledge and skills } \\
\hline \multicolumn{3}{|l|}{$\begin{array}{l}\text { Using critical thinking and problem-solving skills in an } \\
\text { authentic research experience }\end{array}$} \\
\hline \multicolumn{3}{|l|}{ Linking theory and practice } \\
\hline Analyzing data within theoretical/conceptual framework & & \\
\hline $\begin{array}{l}\text { Understanding how to frame research questions, develop/refine a } \\
\text { research design }\end{array}$ & 26 & 8 \\
\hline $\begin{array}{l}\text { Understanding nature of scientific knowledge: its open-endedness, } \\
\text { the nature of scientific "fact," science as "fallible," how scientific } \\
\text { knowledge is built }\end{array}$ & 10 & 3 \\
\hline $\begin{array}{l}\text { Critical thinking/problem-solving skills, in general (i.e., nonspecific } \\
\text { statements) }\end{array}$ & 6 & 2 \\
\hline Subtotal for all gains in the application of knowledge and skills & 178 & 57 \\
\hline \multicolumn{3}{|l|}{ Gains in knowledge and understanding of science and research work } \\
\hline $\begin{array}{l}\text { Greater knowledge; understanding in depth; understanding } \\
\text { theory/concepts; making connections between/within science; } \\
\text { solidifying knowledge }\end{array}$ & 46 & 15 \\
\hline $\begin{array}{l}\text { Consolidating and deepening knowledge through presentation and } \\
\text { teaching }\end{array}$ & 40 & 13 \\
\hline $\begin{array}{l}\text { Increased appreciation of the relevance of coursework to } \\
\text { understanding science }\end{array}$ & 30 & 10 \\
\hline $\begin{array}{l}\text { Developing the temperament necessary for research work: } \\
\text { increased patience and perseverance; increased tolerance } \\
\text { for frustration, setbacks, and failure }\end{array}$ & 19 & 6 \\
\hline $\begin{array}{l}\text { Subtotal for all gains in knowledge and understanding of science and } \\
\text { research work }\end{array}$ & 135 & 43 \\
\hline Total & 313 & 100 \\
\hline
\end{tabular}

more of this linked group of gains were reported and discussed in 56 of the 66 interviews $(84 \%)$, and were described in 178 individual observations. ${ }^{13}$

In the largest (and most basic) of the three levels of gains in the application of knowledge reported in this group (43\%), students shared the experience of coming up against particular research problems that had not been previously addressed and for which there was no ready answer. They also described the powerful impact of realizing that it was up to them to draw on their bank of theoretical knowledge, thinking, and technical skills to arrive at a choice of direction and move the project forward:

When you're faced with kind of a novel problem when there's no right answer yet, and you have to find the right answer, I think research does a good job at teaching those skills. Because you don't have anything to go back and rely on... you're having to do it yourself. (Male biology major)

\footnotetext{
${ }^{13}$ Given our counting conventions described earlier, the maximum count for these three gains across the 56 individual interviews and seven focus groups would be 210 .
} 
Students expressed satisfaction in seeing how theory and practice were linked, deciding how to analyze data within theoretical frameworks, and pulling together their intellectual resources to address "something that mattered" 14 .

One of the more rewarding things, I think, was I took massive loads of data, and there's just tables and tables of data and you're working it up.... And (my advisor) gives me this little mathematical approach saying, "If you work it this way, it'll work out and give you this." And I was skeptical and I was thinking, "Sure. Sure." ... And working this data for days and days, but, sure enough, it kinda culminates to one thing. And I think to see that experimental side work to some sort of mathematical application or theoretical side, I was just kind of amazed by it. (Male chemistry major)

They described how they were now using the problem-solving and technical skills they had acquired:

It really does help you learn to detect your own dumb mistakes. Like, it's easy to think about something conceptually a little bit wrong, and go with that for about a week. But then you look at what you've got, and your spectra don't make any sense.... Then you realize what the problem is. You learn to recognize things like that quicker and quicker the more you do it. (Male physics major)

These experiences contributed to their growing appreciation of the complexity and uncertainty of science as an ongoing process:

I think there's only so much you can get from classroom learning.... You get into the lab and you say, "Okay. This should work." No, it doesn't work! Because there are so many other considerations that you have to make. And that's the kind of thing you can only get from research. (Female chemistry major)

Students also pointed out that aspects of these gains were useful and transferable to other intellectual or professional spheres:

I think on a very basic level you can use these skills in any science field. Just learning how to plan, learning how to be careful, how to take care of mistakes, and recover from mistakes. I think that's something you can really apply to any field. (Female biology major)

Just thinking about things completely, and trying to think of all the possibilities before you plunge into things. So that if you're designing an experiment, you want to know ahead of time, "What are all the possible things that could happen?" and, "How would you explain each result?" And I think that's something I can use in other areas, too. (Female biology major)

As indicated above, many students reached a stage where they were able to use their critical thinking and problem-solving skills in their research work. However, far fewer (11\%) reported going beyond this to attain what Kardash (2) defines as "higher-order skills" and that many faculty hope to see in students as a result of their undergraduate research experiences. Of these reports, $8 \%$ focused on the processes involved in designing a research project. These included a better understanding of how to approach a research issue in different ways; how to work from the relevant literature to identify, choose, draft,

14 This benefit was also reported in three Type 1 studies $(2,3,4)$, and mentioned in four Type 2 accounts $(10,14,23,43)$. 
and refine new research questions; and how to develop methods and procedures to address those questions ${ }^{15}$ :

Just being able to sit down and concentrate on one thing and figure it out and understand.... We work with protein-DNA interactions. And so just for me to look at that and really, really understand it rather than just getting the big overview. And then, actually thinking about the problem critically and creatively and being, "Okay. Now what can I change to have this effect and to have this outcome?" That's a whole new experience for me. (Female chemistry major)

Often embedded in these accounts were the students' sense of excitement and accomplishment at breaking new ground, mixed with a strong sense of responsibility for the process and the outcome.

Three percent (just 10 students) went a stage further. Interrelated with their enhanced understanding of the realties of research, these students described a shift in their perception of "classroom science" as an abstract body of received knowledge, to an appreciation of "real science" as a set of alternative ways to explain and explore natural phenomena. ${ }^{16}$ These reports are of great interest because they demonstrate the potential of effective undergraduate research experiences to enable a more sophisticated understanding of the nature and construction of scientific knowledge. These students found themselves rethinking what it means to call something "a fact," actively questioning the received knowledge and simpler assumptions of their earlier education, ${ }^{17}$ and appreciating the importance of continuing to ask questions:

I think it comes with hands-on work, because as a student you're handed this as fact. . . and you don't question that. But what you find out in research is that a lot of things that people have found out need to be questioned.... We can stand on the backs of people who have figured out... but scientists have been wrong in the past... . You have to do experimental work and explain why it's going that way. (Female chemistry major)

Others found that their research had prompted them to think about the nature of "science" and "truth" and the role that theory and research play in the building and rethinking of "knowledge":

I've made some great realizations.... I think a lot of people think science is truth, this all-encompassing certainty.... And what I found out is that often what research does is just to explain how something could happen, or probably happens, and not necessarily how it does happen. (Female chemistry major)

These reconsiderations were counted as an important benefit of the undergraduate research experience, although they could be unsettling as well as a source of satisfaction:

When you get into the actual process, it's very ambiguous. Everything in science is a model to describe reality. We're not really studying reality as such; we're studying this model of

\footnotetext{
${ }^{15}$ In one Type 1 study, Kardash (2) found that this set of higher level skills was not achieved, either by the accounts of her student samples, or by the faculty who rated their students' progress as researchers. Improvements in students' abilities to approach research problems and design experiments are widely claimed in Type 2 accounts $(14,19,25,26,37,38,39,40)$.

16 This more rarely reported benefit was an important focus of research studies by Ryder, Leach, \& Driver (3) and Rauckhorst (4).

${ }^{17}$ See also two Type 1 studies $(3,4)$.
} 
reality.... I think, having done some research, you really get a sense of what it's all about. (Male physics major)

Taken together, this small number $(11 \%)$ of gains is clearly richer and more complex than "improvements in" critical thinking and problem-solving skills that are mentioned (though not clarified) in a large number of studies. ${ }^{18} \mathrm{We}$ are uncertain at this (first) stage in our analysis of three rounds of student interview data whether smaller numbers of descriptions of these types of intellectual gain are, in some measure, an artifact of students' difficulties in recognizing or describing them. In their first interviews, the interviewer experienced more difficulty in getting students to describe their intellectual progress than other categories of gains. However, the same students seemed to find its dimensions and consequences easier to talk about in the second interviews where, close to graduation, they reflected more on what they had learned overall in their undergraduate education. Faculty may also find these attributes hard to describe (if not to recognize). We will, therefore, leave both possibilities open until a later stage in the analysis.

\title{
Gains in Knowledge and Understanding of Science and Research Work
}

Among the reports of increases in knowledge and understanding, $15 \%$ described a deeper understanding of aspects of their discipline, making connections between and within areas of science, and solidifying existing knowledge. ${ }^{19}$ Some of these gains were discipline-specific:

\begin{abstract}
Well, intellectually I think that it's helped me to understand chemistry better. Not just the chemistry that I happen to be doing in the lab, but also chemistry as a whole, just because my research does relate to many different areas of chemistry. And learning how to look through the primary literature and to really synthesize and understand the information about the project has helped me to better understand other areas of chemistry and pick things up more quickly. (Female chemistry major)
\end{abstract}

It showed me how much I don't know about chemistry! (Female chemistry major)

Students stressed the benefit of seeing how smaller pieces fitted into a broader framework, and/or the ways in which their research had encouraged them to see cross-disciplinary connections:

I've learned to look at the bigger picture and see everything's place inside it. I guess I had kind of like a little microscopic view of things before. Just looking at one specific action of, say, cell development, but never actually thinking about how all these different genes could be interacting. (Male biology major)

Some students reported a greater appreciation of their discipline, or of science, more broadly; others emphasized greater understanding of the content of their courses and why it is important to learn certain things. The experience had enabled them to use what they had learned in class in their research - and the reverse-and had improved their comprehension of ideas introduced in subsequent classes. Others simply enjoyed their science classes more.

${ }^{18}$ See, for example, Type 1 study (2), and Type 2 accounts $(14,16,19,25,26,37,38,39,40,43)$.

19 This gain is reported in three Type 1 studies $(2,3,4)$ and four Type 2 accounts $(10,14,23,43)$. Kardash's (2) student sample rated "relating their results to the bigger picture," and "understanding contemporary concepts in their fields" as two of the four most significant gains from their undergraduate research experiences. 
Students who confessed to struggling with motivation, described the good impact of this experience on their sense of direction and perseverance in classes that followed it.

In $13 \%$ of their reports in this category, students described how two related facets of the undergraduate research experience-learning to present their work and teaching othershad solidified and extended their scientific knowledge. In the following section, we discuss other benefits of presentation experience. However, here, students highlighted the value of preparation and presentation of their work and of teaching others in expanding their knowledge and deepening their understanding by requiring them to explain their projects to others:

I think standing up in front of people and discussing your research is invaluable. I think it's really helpful because you get a better sense of it yourself. (Female chemistry major)

You really have to know what you're talking about.... If they ask you questions, you really have to understand it. (Male engineering major)

Preparing and giving presentations and answering listeners' questions also made students reflect on how much they had learned, both in this process and from the research work itself:

It's nerve-wracking, but I think people asking as many questions as possible about your project is more valuable to you than it is to them, because it shows what you know about your project, and what more you need to know. (Male physics major)

The experience of explaining their work to a wider public and fielding their questions also reduced the common student fear of exposing areas of uncertainty in their understanding. Similarly, students found the experience of teaching gratifying in that helping others to understand complex ideas deepened their own understanding and exposed gaps and areas of uncertainty in their knowledge:

Talking to them—explaining different things—-makes you understand your project in detail. Because, sometimes they will ask some random, but very profound, question that you haven't thought about, and you might have to go back and read it to yourself to come up with an answer for them. (Female chemistry major)

As with presenting and discussing their work, teaching classmates or members of their research groups increased their levels of comfort and confidence in being open about what they did, and did not, know.

Ten percent of observations in this category described a better understanding of the relevance of what they had learned in class or lab to the "real research" in which they were engaged ${ }^{20}$ :

We'll learn about the technique in class, but then... you understand it in a completely different way when you have to actually apply it. (Female biology major)

Their first-hand experience of "doing" science also helped students to understand the many complications and setbacks that scientists encounter in their daily work (6\%). Students commented on the length of time involved, the care needed to make accurate observations

${ }^{20}$ This gain was reported in four Type 1 studies $(5,7,8,9)$, and was claimed as a benefit in six Type 2 accounts $(11,14,20,30,34,43)$. 
and keep detailed notes, how much attention to detail was required, the tedium and repetition of some lab tasks, the long hours researchers worked, and their difficulties in achieving desired results:

You never really think that the scientist spends all this time... you never think anybody runs into a dead-end. Like the geniuses like Einstein, you never think that he ran into a dead-end, but he did. Many people did. And it gave me a better appreciation for it because, to get through all that and to know what we know today in the sciences, is just amazing. (Male physics major)

This was much more than an intellectual appreciation of what goes into research. These students had come to understand that a high incidence of setbacks, errors, repeated procedures, and failed experiments is a normal part of the research process. They realized that research required either a natural or acquired tolerance for these frustrations:

Sometimes you just have to slog through things. That was kinda one of my biggest lessons. Sometimes there're no shortcuts. You just have to get in there and work at it. And it might take a while, but sometimes that's the only way to get it done. (Male engineering major)

Students observed how their faculty mentors dealt with problems, and discovered how they themselves responded to difficulties. ${ }^{21}$ Some noted that they had gained greater patience and perseverance in working on a single project, and had acquired an increased tolerance for frustration, setbacks, and "failure." Indeed, students were apt to use this as a "litmus test" to determine whether or not they were temperamentally suited to a career that included research:

It's helped me to deal with failure in the laboratory. And it's not your fault. It's not anything you could have done. It's just the protocols that worked perfectly for so-and-so don't work for you because of reasons you didn't even think about and nobody thought about. It's helped me to be a better problem-solver, I think, to look at this and say, "Okay, we'll pinpoint what's going wrong. We'll see what other people have done. We'll see why ours is different and how we can change things so that it will work." (Female chemistry major)

Again, students saw aspects of this experience as highly applicable to other arenas of professional and personal life:

I think the perseverance that it takes, the patience to be able to just keep working and not giving up on things, that is something that I think will be useful in other areas-learning to not expect things to happen right away, and suddenly, magically, you have all your results. (Female biology major)

Students' engagement in undergraduate research, thus, provided them with an intellectual and affective appreciation of "real science" at work. It enabled them to bring their own critical thinking and problem-solving skills to bear on research questions, and to apply their theoretical knowledge in practice. They reported gains in the depth of their knowledge and understanding in their own discipline, and made conceptual connections with other disciplines. Some students also gained a more realistic and a deeper understanding of what science research requires, both intellectually and temperamentally, and clearer insights

\footnotetext{
${ }^{21}$ Two recent accounts $(17,18)$ have also discussed the importance to students of close interaction with faculty mentors who model how research is done.
} 
into science as an ongoing, collective process whereby "truths" evolve and are questioned, individual contributions accumulate, and knowledge is built.

Establishing the nature and extent of actual intellectual gains through participation in undergraduate research lies beyond the scope of this kind of research where the focus is upon students' self-perception of changes in their thinking and thinking skills. We hope that other scholars in the fields of learning and learning assessment (C. M. Kardash, manuscript in preparation) will continue to pursue these issues.

\section{GAINS IN SKILLS}

Nineteen percent of all students' observations and also $19 \%$ of their observations on the benefits of undergraduate research described gains in particular skills (Table 2). The largest group of skill gains described in this category (43\%) were improvements in communication skills $^{22}$; the balance $(57 \%)$ was divided between gains in six other types of skills: lab, work organization, computer, reading comprehension, working collaboratively, and information retrieval (Table 5).

\section{Gains in Communication Skills}

Almost one quarter (22\%) of reported gains in all types of skills, and the most oftenmentioned of communication skills per se, were those needed for, and acquired by, presentation, explanation, discussion, oral argument, and defense of students' research work. ${ }^{23}$ By contrast, only a small number of skill observations (7\%) described improvements in scientific and professional writing skills.

In all four of the institutions sampled, individual and group presentation of project work was built into the end-of-summer activities. Indeed, it was one of their most distinctive formal characteristics, and one of several overt teaching activities. Presentations were organized by single departments or across divisions, and all participating students and faculty, as well as many administrators and support staff, made a point of attending. Students were in no doubt about the importance of these occasions; they took them very seriously, and (as reported by their faculty) tended to dress formally. Both students and faculty took pride in describing recent presentations, and in showing the interviewer the resultant posters and demonstration materials.

Students received guidance from faculty advisors and help from their research groups in preparing, discussing, and rehearsing their presentations. Faculty advisors used weekly meetings as an opportunity to build both skills and confidence by offering guidance and practice in how to argue points, answer questions, respond to critiques of their work, and question other researchers in a collegial manner:

Each person gets up and speaks for anywhere from 10 to 30 minutes about what they've done the last week and what they're planning on doing this next week. . . It's quite intimidating because she interrupts you a lot and she asks you a lot of questions, and she wants you to recall a lot of things. And so, from that experience alone, just over the six weeks that we've been doing that, I feel so much better about being on the spot and defending my work. (Female biology major)

${ }^{22}$ Gains in communication skills (in general, rather than in specific) were claimed in nine Type 2 accounts $(10,11,19,20,25,26,28,29,43)$.

${ }^{23}$ In the study of Kardash (2), undergraduates reported an enhanced ability to communicate the results of their research projects and ranked this as the highest of three skills in which they saw appreciable gains from their research experiences. 
TABLE 5

Students' Positive Observations on Gains in Skills

\begin{tabular}{lrr}
\hline \multicolumn{1}{c}{ Quality of Observation } & $N$ & $\%$ \\
\hline Communication skills & 48 & 22 \\
Improvement of presentation skills/ability to defend oral argument & 29 & 14 \\
Improvement, in general (i.e., nonspecific statements) & 14 & 7 \\
$\quad$ Improvement of writing skills & 91 & 43 \\
Subtotal for all gains in communication skills & 48 & 22 \\
Lab/field skills: instrumentation, measurement, technical skills & 23 & 11 \\
Work organization skills: time management, note-taking, & & \\
$\quad$ details of lab management & 20 & 9 \\
Computer skills & 18 & 8 \\
Reading comprehension skills & 10 & 5 \\
Collaborative working skills & 4 & 2 \\
Information retrieval (library/internet research skills) & 123 & 57 \\
Subtotal for all other gains in skills & 214 & 100 \\
Total &
\end{tabular}

Talking their work over with their group on a regular basis helped to shape their research ideas and choice of working methods. The group also helped them build their presentation. Thus, long before public presentation, many students had become very accustomed to an open, critical, mutual exchange of their work in progress:

Tuesday and Thursday, we would all go through what we had discovered so far and present our ideas and say, "Okay... does this make sense to all of you?" You get so deep in it that sometimes things made sense to you that really don't make sense, you know? In mathematics, it's very important-you're building on different things. And if one thing that you built upon doesn't make sense, then the rest of it, you can't say. And so sometimes it was really good to present our ideas and if we were thinking about something the wrong way, somebody else could speak up.... They weren't working on it all the time so they could see what wasn't making sense. (Female mathematics major)

Working initially with their group was seen as a more comfortable way to try out their ideas. As the time drew closer for their college presentations, faculty advisors often gave individual or group practice sessions:

He wanted to sit down with me in a more formal setting and give my presentation to him, just to practice. And I wasn't quite ready. I hadn't quite figured everything out. So I gave it and I knew I was leaving out a lot of things and felt like I still had a lot of work to do. And he just listened to it. He didn't make any criticisms.... He was able to listen to kinda what I knew, and he knew the important things I wasn't getting. And he'd just kinda go to the board and we'd start talking about it, like just after the presentation's over. He wasn't like, "Oh, that was good," or, "That needs some work." He just started talking about the project. And just in those 10 or 15 minutes, I got a much better understanding about what I left out. So, in a very indirect, subtle way, he was able to say, "Okay, this is really what you were lacking, but I don't have to tell you that. We're just going to talk about it, and now you get it." So then the next day, I think the presentation went quite well. (Male chemistry major)

Students also got advice about presentation techniques, and, in some instances, several faculty were involved in the rehearsal. 
The benefits of learning to present and discuss research findings and methods in public encompass rather more than acquiring the know-how to do this. Students described how, with practice and support, they overcame their initial reluctance or anxiety about public speaking. They gained confidence as they became more adept at answering questions and criticisms from the floor:

\begin{abstract}
When someone originally raises their hand, your heartbeat rises a little bit just because you're not sure what they're going to ask, and you're not sure if you're going to be able to answer it. But I think as more and more questions are asked, especially if you've done the research and the whole project, you know, you have a firm grasp of what you did. Either you can answer the question, or if you can't answer it, it's either because you haven't done it yet or maybe it's not relevant to what you did specifically. So I think, after a while, you get comfortable fielding questions. (Male chemistry major)
\end{abstract}

Using the group as a sounding board for ideas long before presentation helps to address one of the most difficult, but professionally significant, personal transitions for students. Learning to give and take critique, and coming to see this as normal professional practice linked to its essential role in the process of building scientific knowledge, goes beyond skills' acquisition. Students described the process of learning to distinguish between personal and professional criticism as a journey in emotional growth:

At the beginning. . I I was, "Oh, I don't know if I could take this all the time"- - just somebody questioning you or doubting you, which isn't necessarily true... but that's what it feels like, at times. But even in the last six weeks, I've been able to mature, and I think I can handle myself a lot easier. (Female biology major)

Most of the student researchers had presented only within their college at this stage, but this is clearly where most of their presentation skills were developed. Beyond this, 21 of the seniors reported that they had traveled with their faculty advisors to make conference presentations, and some were planning to attend undergraduate research symposia. Beyond their in-house practice, this was seen as another step up in skills, experience, and confidence gained:

It was great, because we got so many suggestions just from standing there....I had all these 50 year-old men walking up to me being like, "You don't really know what you're talking about.... I can't see how this would possibly work."... And it's intimidating to try to explain. After the first couple, it got easier. It was nice that they stopped and looked. It was nice to interact with them. They would actually talk to you like colleagues, like, make suggestions. That's actually how we got the whole carbine thing, it was from some of his colleagues that came by. (Female chemistry major)

We shall continue to track the incidence and benefits of professional presentations in the analysis of subsequent interview rounds. However, establishing these numbers with larger samples is more appropriately done using survey methods.

From their experiences of presentation and collegial discussion, students reported an increase in their ability to explain the nature of their research work to colleagues in other fields, and to a wider group of people with a more limited science background. Explaining their research to family and friends was seen as a challenge and as an accomplishment. It was also seen as a way to improve a presentation draft.

A small number of student observations $(N=14)$ described gains in writing skills as part of their undergraduate research experiences, or had received help from their mentor in learning the processes of editing: 
Learning to write for a scientific journal I found even more difficult.... We had something like five major revisions by the end of the summer.... It was a strange feeling, receiving a paper with lots of red ink on it. And I almost felt like I was completely incompetent.... I think it's part of the learning process to recognize when there's a right style, and a right word.... It was very, very useful to me. (Male mathematics major)

Students described how much they (and their draft paper) gained by circulating it to a wider group for critique and suggestions on omissions and clarity. The group was also brought into the editing process as students helped each other develop posters and, in some cases, a group paper. These were not entirely new experiences for many students, but were described as part of an ongoing writing education process at their colleges. However, editing with faculty for journal submission was described as much more demanding.

Very few students entering their senior year (i.e., the majority of our student sample) had, as yet, worked with their mentor on a paper intended for publication. Five students reported that they had coauthored (with their faculty advisor) a published paper; two expected to publish again; and a further 16 expected to publish a paper with their faculty advisors sometime in the future. ${ }^{24}$ Some faculty accounts of student gains from undergraduate research primed us to expect a larger portion of writing gains. ${ }^{25}$ However, although few students were, as yet, working on articles intended for publication, some saw this as forthcoming. ${ }^{26}$ In their last months before, and their first year beyond, graduation, former undergraduate researchers may continue to work with their mentors in making professional presentations, and preparing research articles or proposals. We shall check to see if this is the case. ${ }^{27}$

\section{Gains in Other Skills}

Equal in number to reports of gains in presentation and oral argument, $22 \%$ of students' observations on their gains in skills describe improvements in lab skills. ${ }^{28}$ Students referenced the enhanced range of lab techniques, procedures, and instruments to which their research experiences had exposed them.

Gains in what students often called "practical" skills included an increased ability to organize their work, manage their working time more efficiently, and/or keep good records. These accounted for $11 \%$ of reported gains in skills, and, again, benefits that students saw as transferable to other areas of professional and personal life. The same was also true in the $9 \%$ of reported gains focused on enhanced computer skills. Some accounts linked these skill gains to the career advantages of doing undergraduate research; other accounts focused on the importance of either a working knowledge of a range of computer skills, or of a very specific set of new skills, to the contribution they could make to their project and their field of research, as well as to their subsequent class work.

${ }^{24}$ Only two students reported having seen how their mentor developed a research proposal for funding.

${ }^{25}$ Developing writing skills was included as a program goal in four Type 2 accounts $(20,28,29,46)$. It was offered as an indicator of a successful program, and/or claimed as a benefit by three further Type 2 accounts $(10,11,14)$. Improving writing skills was not, however, included either as a criterion for a successful program or as a demonstrated outcome in the small number of well-designed evaluation studies identified in our literature review. The two student samples in the study by Kardash (2) reported gains in their ability to write a research paper for publication as the least enhanced of the 13 skills rated by students in this study.

${ }^{26}$ Kremmer and Bringle (1) reported that the benefit of publishing came some months after the research experience for a high proportion of their sample.

${ }^{27}$ In six Type 2 accounts $(15,19,26,34,35,47)$, counts of either publications and/or conference presentations are offered as indicators of the success of undergraduate research programs without reference to their value as perceived by students.

${ }^{28}$ Improvements in students' lab skills were reported in six Type 1 studies $(1,2,5,7,8,9)$ and claimed in six Type 2 accounts $(10,11,14,17,19,20)$. 
Eight percent of skill gains statements referenced an enhanced ability to comprehend, analyze, and critique academic literature that had emerged largely as a result of extensively reading original work for their projects. Students spoke of increased confidence to tackle new articles, of the intellectual satisfaction they gained from their reading, and, again, saw these skills as useful and transferable.

Overall, gains in communications skills (especially oral presentation) were, as we have indicated, the single most important group of skill gains cited by students at this stage in their academic careers. As we also note above, across all accounts of skill gains, students emphasized related gains in confidence and other aspects of personal and professional growth. They also highlighted the transferable nature of many gains in the skills category.

\section{CLARIFICATION, CONFIRMATION, AND REFINEMENT OF CAREER/EDUCATION PATHS}

Undergraduate research is often championed for its perceived effectiveness in increasing the proportion of students who choose to enter graduate school. However, both in the literature, and in this study, it is important to distinguish between claims that undergraduate experiences can prompt undergraduates to choose a graduate school career path, and more qualified claims that the experience can clarify, refine, and reinforce such a choice. The nature of what is claimed varies, as follows, across the four types of student benefit statements that we have identified in published material on undergraduate research:

1. In nine articles that include statements of program goals for the undergraduate research programs studied, claims are made for choice of graduate school as a desired outcome. Five accounts $(24,28,32,33,34)$ include encouragement to choose graduate school as a goal of the undergraduate research programs they describe. Four studies $(5,7,9,13)$ describe programs in which the goals specifically include increasing graduate school enrollment; in the latter four studies, increased graduate enrollment for students of color is a particular goal.

2. Studies that hypothesize particular outcomes for the undergraduate research programs that they describe, offer more limited expectations. Four articles $(14,24,50,52)$ predict that the clarification of career goals will be an outcome for students who participate in undergraduate research.

3. Among the large body of accounts that claim particular benefits for undergraduate research programs, but where the methodological basis of the study or account is insufficiently rigorous to substantiate the claims made, five articles $(13,15,18,42,54)$ assert that program participation leads to the choice of graduate school, other advanced degrees, or to professional work in the research field experienced. In one study of engineering alumni (17) participants rated their undergraduate research experiences "as very important for their decision to attend graduate school." Schowen (54) claims that undergraduate research experiences specifically increases the choice of graduate school among women. Three studies $(11,13,48)$ make the more modest claim that participation in undergraduate research encourages greater interest in attending graduate school.

4. The most modest claims for the career-related benefits of undergraduate research are offered by five evaluation studies that employ sound research methods. Three of these studies $(5,7,9)$ found that undergraduate research participation both encouraged greater interest in attending graduate school, and refined or clarified interest by introducing students to new fields or lines of research with bearing for their 
career interests. Two accounts $(39,40)$ discuss undergraduate research participation as confirming an existing interest in graduate school. Only Alexander, Foertsch, and Daffinrud (5) and Foertsch, Alexander, and Penberthy (7) have substantiated the claim that undergraduate research programs can successfully recruit and enroll students into graduate schools. Both of these studies were of programs that specifically target students of color, beginning with early research experiences among a population of students who are the least likely to have prior graduate school knowledge or aspirations. By contrast, Fitzsimmons et al. (9) found that undergraduate research experiences did not change expectations of graduate school among either students of color or women of all races/ethnicities represented in their study.

Thus, we have found in the literature no instance of a well-designed and executed study that shows a causal effect on graduate school (or other professional degree) choice or enrollment among a population of white students. ${ }^{29}$

From a separate analysis of first-round student data, we were able to establish what, at this stage in their thinking, the interviewees intended as career paths. In 203 statements $^{30}$ in which students described their postgraduate intentions

- $30 \%$ indicated a commitment to graduate school in a science field (with a further $1 \%$ in a nonscience field);

- $19 \%$ indicated a commitment to medical school;

- $15 \%$ indicated a career in science and/or in research without specific reference to graduate school;

- $11 \%$ indicated an academic career of some kind;

- $9 \%$ were undecided;

- $7 \%$ expressed a wish to teach (in various settings, including academe);

- $6 \%$ included the intention to take time out before taking the next career step;

- $2 \%$ indicated a career in industry.

We are, as yet, unable to either support or refute the proposition that undergraduate research experiences can prompt the choice of careers that require graduate or professional degrees. This may (or may not) reflect the sampling constraints of this 3-year pilot study, and we plan further field explorations, both in data from same-student cohorts, and beyond. However, we did find evidence that research experiences had clarified, refined, and/or confirmed students' preexisting choice of career directions (including graduate or professional school), and had encouraged longer term interests in research and academic work.

Fourteen percent of all students' observations and $12 \%$ of their positive observations referenced the part played by undergraduate research experiences in shaping career plans (Table 2). The largest group (30\%) of statements in the career-benefits category explained how, in the course of hands-on research experiences, interest in particular careers had been strengthened, choices between areas of disciplinary or research interests had been clarified,

\footnotetext{
${ }^{29}$ Programs that recruit students of color are usually different in character than those for all-comers, in that they often start as bridging programs between high school and college entry, and continue with the same student group through the freshman and sophomore summers-or beyond. Because they recruit students from among those who are the least likely to have considered graduate school as a personal career option, these programs are more likely to demonstrate a positive impact on choice of graduate school than programs starting at the end of the sophomore or junior year with students who have had greater exposure to the idea of graduate-school entry.

${ }^{30}$ The larger number of student statements than students arises because many students had more than one career plan under consideration at this stage.
} 
and the fit between personal interests and particular fields of study had been explored and affirmed (Table 6). ${ }^{31}$

Doing hands-on research was described as helpful in settling participants' questions as to whether their intellectual and disciplinary interests could be turned into a personal, practical, daily working engagement, with research (or with other types of work) based on a particular field of interest. ${ }^{32}$ As with some other benefits we have discussed, this benefit had strong affective and identity-related components. Students often spoke of the result of the process as being able to "see myself doing" particular kinds of work:

I've always had my eyes on medicine... but I think with my chemistry background, and especially with the recent experience, I think I'm much more leaning toward more of an experimental side of medicine.... I could see myself doing pharmaceutical research or something like that. (Male chemistry major)

These students expressed great satisfaction about having settled (at least for the foreseeable future) what the connections would be between their intended area of work, their academic interests, other aspects of their life, and their sense of identity. They had also been enabled to answer the question, "Will I enjoy doing this kind of work?" by seeing what it entailed in ways that were unavailable to them in the classroom. Some students were enabled to make or confirm choices, or refine their ideas about, fields, subspecialties, or methodologies that competed for their interest; some had discovered a new or related field that kindled or affirmed their intellectual direction. The students in another group were interested in the idea of research as a career, but, until their current research placement, had lacked focus on an area that held their interest. This was also one of several places in the data where we saw the importance of hands-on experience in clarifying for an undergraduate whether they were temperamentally suited to research as a mode of work:

\begin{abstract}
A lot of people, when they see the frustrations and the dead-ends and the hours of work spent, they run away... (they) don't want to do that.... I think that's good if they do research when they're an undergraduate. Because if I would have (decided)... "Oh, man, I can't handle this. I don't want to do this,"... then I could have switched my major or my focus. . . . Now I know. (Male physics major)
\end{abstract}

Thus, in one way or another, all of the observations in this group reflect the clarifying, confirming, and refining benefits of hands-on research experiences.

The second largest group (25\%) of career-planning benefits also included clarification and reinforcement of career ideas, but was specifically focused on graduate school plans. Some students mentioned how long they had been thinking about going to graduate school, and described their research experiences as "settling the matter," sometimes after a period of uncertainty:

Up until this year I had always been dead set on grad school, no question..... I guess about part way through the year I was sort of wondering whether I really wanted to continue on in grad school.... But I really do think—after getting back into research—that I really want to go on in grad school. (Male chemistry major)

\footnotetext{
${ }^{31}$ One Type 1 study (1) and three Type 2 accounts $(18,42,54)$ discuss the positive impact on career choices of working professionally in particular fields without reference to graduate school or research.

32 This benefit is also reported in Fitzsimmons et al. (9). Broader gains in which undergraduate experiences were found to clarify or validate students' incoming interest were claimed in six Type 2 accounts $(10,15,18,34,43,54)$.
} 
TABLE 6

Students' Positive Observations on How Undergraduate Research (UR) Clarified, Confirmed, Refined Career/Education Paths

\begin{tabular}{lrr}
\hline \multicolumn{1}{c}{ Quality of Observation } & $N$ & $\%$ \\
\hline UR clarified/confirmed, student's interest in field of study; aided student in & 39 & 30 \\
deciding which area of study to pursue; provided concrete recognition of & & \\
fit between own interests and field of study & 33 & 25 \\
UR clarified/confirmed level of interest in graduate school & 18 & 14 \\
UR increased probability that student will go on to graduate school & 16 & 12 \\
UR increased student's interest/enthusiasm for field of study & 10 & 8 \\
UR introduced student to new field of study & 8 & 6 \\
UR stimulated/confirmed interest in research career & 7 & 5 \\
UR experience clarified that a research career is not what student wants & 131 & 100 \\
Total & & \\
\hline
\end{tabular}

However, some students made it clear that, although they had settled on graduate school as a first step, they did not feel totally committed to a life in research and might do something different with their doctoral training. A further 14\% described their research experiences as having increased the probability that they would go to graduate school. ${ }^{33}$ These were students who spoke of enjoying their summer work, but who were still undecided about graduate school entry as they entered their senior year.

All of the statements that describe the influence of summer research experiences on students' thinking about graduate school indicate prior knowledge and consideration of graduate school. None assert that the experience had introduced the idea, or prompted a choice not previously considered. Indeed, all of the speakers were some way along in the process of taking decisions that they had mulled for some time. Another group of statements fell short of commitment, either to graduate school, or to any particular career: in $12 \%$ of the descriptions in this career-related category, students spoke of increased interest in, and enthusiasm for, their field of study as a consequence of their undergraduate research experiences. ${ }^{34}$ They did not, however, project these gains into education or career plans. However, as in other categories, we noted elements of self-discovery embedded in the process of exploring research in their discipline, particularly, the allaying of doubts that this kind of work was "for them," and that their interest in the work was sufficient to sustain a possible career.

A small, but important, group of seven students described how, in the course of doing hands-on research, they had discovered that research was not the kind of career that they wanted. The experience had shifted their focus away from research to types of work that better supported their interests or temperament. We counted these realizations and the processes that shaped them as gains rather than as negative outcomes of the research experience because the students reported them in this light. This is the only group for whom we can report career choices per se arising from students' research experiences. As we have illustrated, by far the most common career-related reports portray the research experience as having clarified, refined, or reinforced their pre-existing career aspirations,

\footnotetext{
${ }^{33}$ Four Type 2 accounts $(11,13,34,54)$ claim that undergraduate research participation encourages greater interest in attending graduate school.

${ }^{34}$ Increased interest in and enthusiasm for their field of study was found to be a benefit in four Type 1 studies $(5,7,8,9)$ and was claimed as a benefit in 11 Type 2 accounts $(13,21,24,25,26,28,29,30,32,33,37)$.
} 
whether graduate-school-related or not. The findings, to date, from this study, thus support those evaluation studies that report clarification of career direction, rather than career choice, as the dominant contribution of research experiences to undergraduates' career-path development.

Two broader gains, however, are discernable across all of the career-related categories of response. They are, first, stimulation and renewal of interest in science and mathematics, both by direct engagement and by discovery of hitherto unknown areas of knowledge. An enhanced appreciation and enjoyment of science might also be added to the list of benefits from undergraduate research that are highly transferable and that give the experience merit beyond its actual or potential role in shaping or confirming career choices. The second overarching benefit is evidenced in students' reports of the self-discoveries that research experiences afford. The experience of trying out aspects of the research role and its working relationships enables students to "make up their minds" and "see themselves" (or not) in the kinds of work to which a graduate education in the sciences might lead.

It is worth comparing this set of benefits with the results of a separate analysis in which we categorized undergraduates' statements about their reasons for undertaking undergraduate research. Overall, students' motives were grounded in intrinsic disciplinary interests and/or a desire to experience the nature of research as work $(71 \%)^{35}$ rather than instrumental concerns such as resume enhancement $(17 \%)$ or other pragmatic considerations. Clarifying whether their intellectual interests and the nature of research work would converge sufficiently to support a particular career direction accounted for only $16 \%$ of all students' reasons for undertaking undergraduate research; career clarification or choice was not, then, a strong motivator. However, along the way, as described above, many students found themselves enabled to think more clearly about their career ideas.

Because of the considerable ongoing interest in the proposition that undergraduate research may play a role in promoting career choices in the sciences-especially the decision to continue on to graduate school-we shall continue to track this issue in our analysis of the second and third (i.e., postgraduate) rounds of student interviews.

\section{ENHANCED CAREER/GRADUATE SCHOOL PREPARATION}

In this group of observations, students assessed aspects of their research experiences as having provided a good preparation for their future endeavors. Gains of this type were $9 \%$ of all observations (Table 2) and 9\% of students' positive observations (Table 7). Many of these comments refer to gains in career preparation, including graduate school. However, students often added the suggestion that undergraduate research had afforded them a broader preparation for work in many settings.

The largest group (36\%) of gains in this category portrayed undergraduate research as a useful preparation for careers and/or the job market because it offered "real-world work experience." 36 For those bound for graduate school, it gave students the opportunity to see what working in science research would be like and to feel confident that they could handle its demands and modes of work. ${ }^{37}$ Research experiences were also seen as a useful

\footnotetext{
${ }^{35}$ Of all students' statements on their motivations for participating in undergraduate research, $41 \%$ indicated intrinsic interest, $16 \%$ indicated clarification of career interests, and $14 \%$ indicated engagement with faculty/peers and projects.

${ }^{36}$ The claim that students value research as a real-world work experience that prepares them for future careers is cited as a gain in four Type 1 studies $(5,7,8,9)$ and is claimed as such in many Type 2 accounts (e.g., 13,14,15,20,24,25,33,38,40,43).

${ }^{37}$ One Type 2 account, Schowen (54) describes undergraduate research as a good preparation for graduate school in that it eases the transition of undergraduates into graduate-level work.
} 
TABLE 7

Students' Positive Observations on How Undergraduate Research (UR) Enhanced Career/Graduate School Preparation

\begin{tabular}{lrr}
\hline \multicolumn{1}{c}{ Quality of Observation } & $N$ & $\%$ \\
\hline UR provides "real-world work experience" & 38 & 36 \\
UR offers the opportunity to network with faculty, peers, other scientists & 29 & 28 \\
UR enhances resume: good for graduate/medical school prospects & 19 & 18 \\
UR provides exposure to new opportunities/experiences & 8 & 8 \\
UR is good for current education: good preparation for senior thesis, & 5 & 5 \\
$\quad$ coursework & 4 & 4 \\
Conference attendance offers new opportunities for networking/exchange & & \\
$\quad$ of ideas & 1 & 1 \\
Working collaboratively enhances career/graduate school preparation & 1 & 1 \\
UR enhances career preparation, in general & 105 & $100^{\text {a }}$ \\
Total &
\end{tabular}

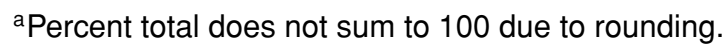

preparation for a variety of work and nonwork situations. Students referenced gains in understanding what such work might be like, competence and confidence in doing the work, and know-how that could be transferred from one context to another. Students who were still undecided about their career paths, or those who had decided that research was not for them, nevertheless acknowledged the value of the experience, and the transferability of the insights, work skills, and marketable experiences they had acquired.

Some students ( $28 \%$ of this category) reported that they learned from their mentors that it was legitimate to contact colleagues in their field to discuss research issues, learn about work opportunities, or draw attention to their work. Learning from faculty advisors how to develop and use such a network was part of their professional socialization. ${ }^{38}$ Faculty were described as taking an active role in professional placement. Students valued letters of recommendation that reflected knowledge of their research work, and referrals to other scientists and professionals in research and industry.

Again, from our separate analysis of students' reasons for entering undergraduate research programs, the two most commonly expressed motivations were intrinsic interest and exploration of the nature of the work: $29 \%$ of statements described undergraduate research as an opportunity to discover how well doing research aligned with their intellectual interests, and/or to explore research as "real work."

We were interested to see how few students described their undergraduate research experiences predominantly in instrumental terms, that is, as valuable because of their capacity to enhance students' resumes. No student described the benefits solely in this way, but some saw this as a bonus: $18 \%$ of comments on the "career preparation" category made a specific reference to undergraduate research as an experience that would increase their appeal to medical and graduate schools, or give them "an edge" in marketing their skills to employers. This finding also matches students' motivational statements (analyzed separately) of which $17 \%$ spoke to the instrumental value of undergraduate research in support of particular career aspirations.

A smaller number of observations in this category (8\%) described exposure to new career-related experiences and opportunities. Most significant among these was making a

\footnotetext{
${ }^{38}$ Various facets of professional socialization in undergraduate research are discussed in two Type 2 accounts, viz., Dunn and Phillips (20) and Nikolova Eddins et al. (26).
} 
presentation at a professional conference. This drew those students who experienced it into the community of their discipline with its modes of conversation and exchanges of ideas. Having their work taken seriously, and their career aspirations affirmed, by senior colleagues were powerful experiences that helped to bond students to their chosen career paths. ${ }^{39}$

\section{CHANGES IN ATTITUDES TOWARD LEARNING AND WORKING AS A RESEARCHER}

In this small category (4\%; Table 2$)$, most (86\%) of the observations concern shifts in attitudes toward learning, and their consequences (Table 8). These included having learned to work independently, relying less on faculty for direction (both in their projects and class work), and willingness to take on greater responsibility for the direction of their projects. ${ }^{40}$ Learning to work independently brought further gains, including a greater sense of selfreliance, and more confidence in their own abilities. This was part of a process in which students began by questioning faculty at regular intervals about what to do next. Over time, as they began to work things out for themselves (and/or with their research group), their questions to faculty changed to, "I'm thinking of doing X; what do you think?" This was evident to students as they looked back over one or more research experiences:

Last summer I pretty much did what he told me. But this summer I felt like I've been a much more active part of the team saying, "Okay. If you think this would work, then why don't we do this?" (Female chemistry major)

Students now saw themselves as thinking and working more independently and taking more responsibility for their work. They described how they now took an active role in managing their projects, were careful and accurate in doing their work, felt responsible for solving problems and meeting deadlines, and felt obligated to finish the projects that they had come to see as "theirs":

I was in the lab eight hours a day and really working on large-scale projects and really having to start dealing with the issues of tedium and failure and, "This isn't just for me to write up in my lab book and turn in and get a grade. This is something that could eventually be published, that other people could base work on." It's more important for me to make sure that I'm doing it right, and that I record everything. (Female chemistry major)

The confidence that comes with knowing you can successfully learn for yourself something that was previously unknown, or can work out a problem on your own, also transferred to subsequent college work.

In the smaller (14\%) of the two groups of observations comprising this category, students reported that making a piece of the research work their own had prompted a shift in their attitudes toward learning itself. ${ }^{41}$ They described the intrinsic pleasure they now took in "figuring out on your own" how to address pieces of their research puzzles.

This group of gains is modestly represented compared with some others. However, we shall return to these issues in our analysis of students' understanding of the processes

\footnotetext{
${ }^{39}$ Seeking to work closely with their faculty advisor and to belong to the research community was also offered as a reason for wishing to undertake undergraduate research in $14 \%$ of students' motivational statements.

${ }^{40}$ Learning to work independently was cited by one Type 1 study (Fitzsimmons et al. (9)) and the shift from passive to more active learning appears in three Type 2 accounts $(19,23,25)$.

${ }^{41}$ One Type 2 account, Strassburger (43) also proposes that undergraduate research increases students' intrinsic interest in learning and makes them better, more serious students.
} 
TABLE 8

Students' Positive Observations on Changes in Attitudes Toward Learning
and Working as a Researcher

\begin{tabular}{lcr}
\hline \multicolumn{1}{c}{ Quality of Observation } & $N$ & $\%$ \\
\hline $\begin{array}{l}\text { Increased willingness to take on responsibility for the project; } \\
\text { gains in learning to work independently, formulate own ideas, }\end{array}$ & 36 & 86 \\
$\quad$ and contribute to project direction \\
$\begin{array}{l}\text { Greater intrinsic interest in learning: increased motivation, } \\
\quad \text { attention to detail }\end{array}$ \\
\begin{tabular}{l} 
Total \\
\hline
\end{tabular}
\end{tabular}

whereby the gains that they describe arise. ${ }^{42}$ The related benefits of learning to work with increasing degrees of independence from faculty, assuming increasing degrees of responsibility for the progress of the work, and bringing to it an increased intrinsic interest in learning and discovery, are more than discrete gains. They also contribute to the larger process by which undergraduates bond to science as a communal enterprise, and acquire the motivation to engage in science as a career. Those students who do not see changes of these kinds in themselves are, we posit, unlikely to choose a research-based career path.

\section{SUMMARY AND DISCUSSION OF FINDINGS}

The findings presented here confirm, in many instances, faculty claims about the benefits of hands-on research experiences for undergraduates; however, in other significant ways they do not. They suggest a relative importance for benefits that differs from many accounts, and some claimed benefits are either missing or apply to relatively small numbers of students. We did not, for instance, find that a large proportion of undergraduate researchers had presented posters or papers at conferences, or reported improvements in their formal, scientific writing skills. We counted 21 students who had attended a conference with their advisors, of whom five had presented a poster and seven a paper. Only five students had helped to coauthor a scholarly paper with their advisors (although a further 16 expected to do so in the future); only $7 \%$ of skill-gain statements mentioned the experience of working with their advisors to draft and edit papers. By contrast, students cited gains in communication as their most important set of skill gains (43\%). The most often-mentioned (22\%) of these were gains in their ability to explain, present, discuss, and defend their work to peers, advisors, and other faculty, whether within their institutions or in professional conferences. The institutional practice of holding formal presentations of work at the end of each summer research program was largely credited for this (although, for the minority who presented at professional conferences, the effect was even more powerful). Both of these gains were commonly cited as "the very best thing about this experience" and (in answer to our specific questions) were judged as more important at this stage in their undergraduate careers than the gains in formal writing and editing. Students also saw these gains as highly relevant to their career preparation, and as helping to settle the question of "whether I belong" in science, academe, or research. As such, they are both "gains" and elements in the achievement of other gains.

\footnotetext{
${ }^{42}$ We have a large body of text data that reference the processes by which the gains that we report are acquired. These data include students' accounts that describe their shifts in attitude toward more independence in their work and learning, and toward ownership of their projects. Only those accounts that specifically identify these processes as gains, in and of themselves, are counted and discussed in this section.
} 
We also found no support for the proposition that undergraduate research experiences had prompted rising seniors to choose particular careers (including entry to graduate or professional schools). The exceptions were seven students who decided not to pursue a research career as a direct result of their experiences with the realities of research work. However, there was considerable evidence that their research experiences had clarified, refined, or confirmed students' pre-existing choice of career directions (30\% of the "career clarification" category) or had encouraged longer term interests in research and academic work ( $45 \%$ of the "career clarification" category ${ }^{43}$ ). This may be an artifact of interviewing students at a late stage in their undergraduate careers. It is also possible that many students enter colleges of the type represented in our sample with a predisposition to enter graduate or professional school. We shall, therefore, in the final round of interviews with our whole student sample (all of whom have now graduated), explore the relative importance of factors that have shaped their career-related thinking and action, including their precollege aspirations and undergraduate research experiences.

Notwithstanding these caveats, the finding that $91 \%$ of students' evaluative statements describe specific benefits lends substantial support to the proposition that undergraduate research is an educational and personal-growth experience with many transferable benefits. ${ }^{44}$ It is also distinctive that student accounts largely reference intrinsic merits of research experiences rather than extrinsic measures of program success that characterize institutional claims. The intrinsic nature of student-perceived benefits is also matched by the low level of instrumentalism in student motivations for undergraduate research participation compared with their high level of intellectual interest and desire to experience the work of research. Few students described their research experiences largely as a means to improve their career prospects, and no student described its benefits solely this way.

This is not to say that students do not value some outcomes that are valued by faculty advisors. This is most clearly seen in the category "thinking and working like a scientist," where over one-half of students' benefit statements (57\%) reference what Kardash (2) defines as "higher-order inquiry skills." We note in students a process that is encouraged by active engagement in research: many students improve their ability to bring their knowledge, critical thinking, and problem-solving skills to bear on real research questions; some students go further, gaining insights into how to generate and frame research problems so they can be approached scientifically; and a few develop a clearer understanding of how knowledge is constructed by seeing the implications of their research design choices for the certainty of the answers thus generated. ${ }^{45}$ Descriptions of the stage that they had reached in this process were offered by 64 of the 76 students, and accounted for $16 \%$ of all benefit statements. This finding comes in contrast to more mundane expectations that students will "learn more" about their discipline, or improve their laboratory skills. Gains in, and consolidation of, knowledge and deepening of understanding are, as we have discussed, far more than mere accretion. Students see themselves applying what they know directly to their research, making connections between bodies of knowledge, reflecting on their thinking and discussing it with others, and building a more subtle appreciation of science as a process.

However, the most distinctive characteristic of students' reports of benefits from undergraduate research, considered as a whole, is their focus on personal/professional transitions. Overwhelmingly, students define undergraduate research as a powerful affective,

\footnotetext{
${ }^{43}$ Table 6: $25 \%$ (clarified interest in going to graduate school), $14 \%$ (increased probability of going to graduate school), and $6 \%$ (confirmed interest in research career).

${ }^{44}$ Bunnett (47) is one of the few authors who argue that all students who participate in undergraduate research will benefit, not just those planning a research career.

${ }^{45}$ As indicated earlier, the respective proportions of these student observations were 43,8 , and $3 \%$ of the "thinking and working like a scientist" category.
} 
behavioral, and personal-discovery experience whose dimensions have profound significance for their emergent adult identity and sense of direction. All entries in two categories ("personal/professional gains" and "changes in attitudes to learning and working as a researcher") record growth in confidence, independence, responsibility for the direction and quality of their projects, and collegiality in their working practices. Every other benefits category also contains evidence of these transitions. Collectively, personal/professional transitions (counted across all gains' categories) account for 58\% of all student gains cited-a finding that we offer as among our strongest.

Some part of these gains might be seen as aspects of "professional socialization" in which apprentices in any field begin to absorb its norms, practices (and in some professions, its approved personae), as well as the knowledge required to be proficient practitioners. Indeed, for science as a profession, this process is highly functional in assuring that the next generation of scientists enter with appropriate understandings, attitudes, and skills. However, in reflecting on the ways in which they see themselves as positively changed by their undergraduate research experiences, students consistently stress the relevance and transferability of their gains to different careers and life situations. These benefits cannot be dismissed as purely "personal." Gains in confidence, for example, specifically reference a sense of empowerment to make a contribution to science by bringing thinking and technical skills to bear upon research problems. Feeling confident that they can work independently and creatively as researchers accounted for nearly three quarters (74\%) of all student reports in the "personal/professional gains" category-which was one of the two largest groups of gains reported. Students were also clear in identifying the sources of their increased confidence to "do science." Important among these were learning to work collegially with faculty and their research peers and the discovery that faculty advisors and their colleagues took their work seriously.

Students described how these transitions had occurred and their significance, for example, in developing their confidence and independence as young working scientists, and in clarifying or affirming their career direction. In terms of their significance for professional socialization, the most critical of these processes were recognition of the normality of frustrations, slow pace, and setbacks in research, and discovering the degree to which they were able to tolerate, even relish, the intellectual and personal challenges these entailed; learning to give and take collegial critique of ideas and understanding its scientific importance; and recognition that they had, along the way, taken "ownership" of the project and assumed an independent sense of responsibility for its progress.

From our interviews with faculty advisors, we suspect that they are very aware that the experience of research promotes several kinds of "growth" in their young colleagues that has profound personal and professional significance. This awareness also seems to inform faculty's encouragement or selection of particular students in whom they notice attributes of temperament, as well as intellect that they predict will respond fruitfully to a hands-on research experience. How well these suspicions reflect substance will become clearer as we move into our next piece of analysis that will compare and contrast faculty advisors' perceptions of the benefits that they predict, plan for, or observe in their undergraduate researchers with those identified by their students. However, it is intriguing that this large group of personal/professional transitions identified by students as benefits of their undergraduate research is not well represented in the literature. This may arise from normative evaluation of undergraduate research by a set of extrinsic institutional criteria. It may also reflect the traditional unease of academe with the realm of affective, nonintellectual phenomena. Apparent disattention to the powerful impact of these experiences on young people-and their consequences for professional preparation-while focusing on such issues as how many of them choose graduate school is, perhaps, to miss the point. 
This study grew out of a series of discussions between Elaine Seymour, David Lopatto, and a group of undergraduate research program directors that began at an NSF-AIRE (Award for the Integration of Research and Education) meeting. Four of the 10 awardees (Grinnell, Harvey Mudd, Hope, and Wellesley Colleges) funded the early stages of this research with support from AIRE grants and Deans' Office funds. Most of the research was supported by an NSF-ROLE grant (\#NSF PR REC-0087611). J. Swartz (Grinnell College), S. Wettack (Harvey Mudd College), J. Gentile (Hope College), and M. Allen (Wellesley College) have offered guidance throughout the study as members of its grant steering committee and help in arranging the site interviews. The researchers wish to thank the NSF and the four participating colleges for their financial and practical support; the members of the steering committee for their advocacy of the project and ongoing help and advice; and the administrative assistants at each college who provided sample lists and made all of the arrangements for the site interviews. They are S. Peterson and V. McKee (Grinnell College), L. Wilde (Harvey Mudd College), T. A. Arndt (Hope College), and R. King and K. Thomason (Wellesley College). Most especially, the researchers thank the faculty and students at the four colleges for their generosity and openness in giving interviews. We hope that they, and all who have enabled this work, will regard its emergent findings as truthful, useful, and validating.

\section{REFERENCES}

Alexander, B. B., Foertsch, J. A., \& Daffinrud, S. (1998, July). The Spend a Summer with a Scientist program: An evaluation of program outcomes and the essential elements of success. Madison, WI: University of Madison-Wisconsin, LEAD Center.

Alexander, B. B., Lyons, L., Pasch, J. E., \& Patterson, J. (1996, June). Team approach in the first research experience for undergraduates in botany/zoology 152: Evaluation report. Madison, WI: University of Wisconsin-Madison, LEAD Center.

Bunnett, J. (1984). The education of butchers and bakers and policy makers. Journal of Chemical Education, 61(6), 509-510.

Byrd, G. P., Ballentine, R. J., Stamm, A. J., Weinbeck, R. S., \& Chermack, E. E. (1994). Some experiences with the National Science Foundation's Research in Undergraduate Institutions program. Bulletin of the American Meteorological Society, 75(4), 627-630.

Chaplin, S. B., Manske, J. M., \& Cruise, J. L. (1998). Introducing freshmen to investigative researchA course for biology majors at Minnesota's University of St. Thomas. Journal of College Science Teaching, 27(5), 347-350.

Christman, J. (1991). Supplementing education with research. Proceedings of the 7th Annual Technical and Business Exhibition and Symposium (Paper 91-808, pp. 236-237). Huntsville, AL: Huntsville Association of Technical Societies.

Costa, M.F.M. (1997). Teaching by research at undergraduate schools: An experience. Proceedings of the SPIE: The International Society for Optical Engineering, 3190, 217-227.

Dean, G. F. (1991). Research experiences for an undergraduate initiated by the National Science Foundation. 7th Annual Technical and Business Exhibition and Symposium (Paper 91-810, pp. 246-250). Huntsville, AL: Huntsville Association of Technical Societies.

De La Garza, J. M., Anderson, S. K., \& Lee, J. A. N. (1991). Undergraduate research experience through summer internships. Engineering Education, 81(3), 384-385.

Dukes, R. J., Kubinec, W. R., \& Nations, H. L. (1996). Undergraduate research for majors and nonmajors. Proceedings of the Astronomical Society of the Pacific Conference Series, 89, 195-196.

Dunn, J. G., \& Phillips, D. N. (1998). Introducing second-year chemistry students to research work through mini-projects. Journal of Chemical Education, 75(7), 866-869.

Fitzsimmons, S. J., Carlson, K., Kerpelman, L. C., \& Stoner, D. (1990, March). A preliminary evaluation of the research experiences of the Research Experiences for Undergraduates (REU) Program of the National Science Foundation (Center for Science and Technology Policy Studies). Washington, DC: ABT Associates.

Fletcher, L. S. (1993). The role of engineering in undergraduate engineering education. Proceedings of the AIChE Symposium Series, 89(295), 520-525. 
Foertsch, J. A., Alexander, B. B., \& Penberthy, D. L. (1997, June). Evaluation of the UW-Madison's summer undergraduate research programs: Final report. Madison, WI: University of WisconsinMadison, LEAD Center.

Foertsch, J. A., Millar, S. B., Squire, L. L., \& Gunter, R. L. (1997). Persuading professors: A study of the dissemination of education reform in research institutions (Vol. 5). Madison, WI: University of Madison-Wisconsin, LEAD Center.

Gates, A. Q., Teller, P. J., Bernat, A., \& Delgado, N. (1998). Meeting the challenge of expanding participation in the undergraduate research experience. Proceedings of the Frontiers in Education Conference, 3, 1133-1138.

Gueldner, S. H., Clayton, G. M., Bramlett, M. H., \& Boettcher, J. H. (1993). The undergraduate student as research assistant. Nurse Educator, 18(3), 18-21.

Halstead, J. (1997a). Council on Undergraduate Research: A resource (and a community) for science educators. Journal of Chemical Education, 74(2), 148-149.

Halstead, J. (1997b). Association report: Council on Undergraduate Research. An investment in tomorrow: Undergraduate research students meet members of congress. Journal of Chemical Education, 74(8), 892-893.

Holme, T. A. (1994). Providing motivation of the general chemistry course through early introduction of current research topics. Journal of Chemical Education, 71(11), 919-921.

Humphreys, S. M. (1997). Summer undergraduate program in engineering research at Berkeley. Proceedings of the Frontiers in Education Conference, 3, 1137-1139.

Jones, M. (1991). The marriage of academics and research: Its value to an undergraduate. 7th Annual Technical and Business Exhibition and Symposium (Paper 91-809, pp. 241-244). Huntsville, AL: Huntsville Association of Technical Societies.

Kardash, C. M. (2000). Evaluation of an undergraduate research experience: Perceptions of undergraduate interns and their faculty mentors. Journal of Educational Psychology, 92(1), 191-201.

Kitto, K. L. (1998). Innovative research and laboratory experiences for undergraduate students. Proceedings of the Frontiers in Education Conference, 3, 1128-1132.

Kremmer, J. F., \& Bringle, R. G. (1990). The effects of an intensive research experience on the careers of talented undergraduates. Journal of Research and Development in Education, 24(1), 1-5.

Krochalk, P., \& Hope, E. (1995). A framework for integrating faculty discipline-related research with classroom teaching and learning. Journal on Excellence in College Teaching, 6(2), 3-15.

Kurland, M., \& Rawicz, H. (1995). Involving students in undergraduate research and development: Two perspectives. Proceedings of the Frontiers in Education Conference, 2, 4C1.1-4C1.6.

Mabrouk, P. A., \& Peters, K. (2000, September). Student perspectives on undergraduate research (UR) experiences in chemistry and biology. CUR Quarterly, 21(1), 25-33.

Madler, R. A. (1998). Genesis of an undergraduate research experience. Proceedings of the Frontiers in Education Conference, 3, 1127.

Manduca, C. A. (1997). Learning science through research: The Keck Geology Consortium undergraduate research program. Geotimes, 42(10), 27-30.

McCurdy, D. L., Buckner, B., \& Baughman, R. G. (1998, Dec.). Characteristics of the culture of undergraduate research in a liberal arts and sciences university. Council on Undergraduate Research Quarterly, 19(2), 73-79.

Morley, R. L., Havick, J. J., \& May, G. S. (1998, July). An evaluation of the Georgia Tech summer undergraduate program of research in electrical engineering for minorities. Journal of Engineering Education, 87(3), 321-325.

Nagda, B. A., Gregerman, S. R., Jonides, J., von Hippel, W., \& Lerner, J. S. (1998). Undergraduate student-faculty research partnerships affect student retention. The Review of Higher Education, 22(1), 55-72.

Nikolova Eddins, S. G., \& Williams, D. F. (1997). Research-based learning for undergraduates: A model for merger of research and undergraduate education. Journal on Excellence in College Teaching, 8(3), 77-94.

Nikolova Eddins, S. G., Williams, D. F., Buschek, D., Porter, D., \& Kineke, G. (1997). Searching for a prominent role of research in undergraduate education: Project interface. Journal on Excellence in College Teaching, 8(1), 69-81. 
O'Clock, P. M., \& Rooney, C. J. (1996). Exposing undergraduates to research through a mentoring program. Journal of Accounting Education, 14(3), 331-346.

Orthlieb, F. L., \& Fewster, J. B. (1994). Undergraduate laboratory research as a primary mode of education and not just for majors. Proceedings of the ASEE Annual Conference, 1, 1465-1468.

Parsons, M. L., \& Bentley, G. E. (1975). A format for undergraduate research. Journal of Chemical Education, 52(6), 396-397.

Powers, J. W., \& Black, D. G. Jr. (1975). Report of a conference on research at the undergraduate level. New York: Research Corp.

Powers, J. W., \& Black, D. G. Jr. (1976). Research in the undergraduate college: Faculty involvement in research benefits both students and faculty. Journal of College Science Teaching, 5(3), 171-172.

Rauckhorst, W. H. (2001, July). Measuring the impact of the undergraduate research experience on student intellectual development. Paper presented at Project Kaleidoscope Summer Institute, Snowbird, UT.

Rogers, E. (1995). Diffusion of innovations (4th ed.). NewYork: The Free Press.

Ryder, J., Leach, J., \& Driver, R. (1999). Undergraduate science students' images of science. Journal of Research in Science Teaching, 36, 331-346.

Sabatini, D. A. (1997). Teaching and research synergism: The undergraduate research experience. Journal of Professional Issues in Engineering Education and Practice, 123, 98-102.

Sanzone, G. (1977). Undergraduate research in chemistry: A liberal arts subject. Journal of Chemical Education, 54(9), 566-568.

Schamel, D., \& Ayres, M. (1992). The minds-on approach: Student creativity and personal involvement in the undergraduate science laboratory. Journal of College Science Teaching, 21(4), 226-229.

Schowen, K. B. (1998). Research as a critical component of the undergraduate educational experience. Assessing the value of research in the chemical sciences: Report of a workshop. Washington, DC: National Academy Press.

Schulz, W. G. (1998). Research hones undergraduates: Council on Undergraduate Research helps educators interest students in science. Chemical and Engineering News, 76(31), 43-45.

Seago, J. (1992). The role of research in undergraduate instruction. The American Biology Teacher, 54(7), 401-405.

Seidel, J. V. (1998). The Ethnograph: A program for the computer assisted analysis of text-based data (Version 5.0). Qualis Research. Thousand Oaks, CA: Scolari Sage Publications Software.

Shellito, C., Shea, K., Weissmann, G., Mueller-Solger, A., \& William, D. (2001). Successful mentoring of undergraduate researchers: Tips for creating positive student research experiences. Journal of College Science Teaching, 30(7), 460-464.

Spencer, J. N., \& Yoder, C. H. (1995). The past two decades of undergraduate research. Journal of Chemical Education, 72(2), 146-147.

Stevens, J., \& Reingold, D. (2000). The role of research in undergraduate chemical education. Spring '00 CONFCHEM. Retrieved April 2000, from http://www.chem.vt.edu/confchem/ 2000/a/stevens/researchrole.html.

Strassburger, J. (1995). Embracing undergraduate research. American Association of Higher Education Bulletin, 47(9), 3-5.

Voight, P. A. (1996, Nov.). Optimizing student research: Forming partnerships with undergraduate honors research programs. Paper presented at the 82nd Annual Meeting of the Speech Communication Association, San Diego, CA.

Weal, S., \& Clarke, S. R. (1996, Aug.). Independent research for undergraduate students. Proceedings of the 32nd Operational Research Society of New Zealand Conference (pp. 167-172). Christchurch, New Zealand.

Zydney, A. L., Bennett, J. S., Shahid, A., \& Bauer, K. W. (2002). Impact of undergraduate research experience in engineering. Journal of Engineering Education, 91(2), 151-157. 